\title{
The Shape of Water in Zeolites and its Impact on Epoxidation Catalysis
}

Daniel T. Bregante, ${ }^{1}$ Matthew Chan, ${ }^{1}$ Jun Zhi Tan, ${ }^{1}$ E. Zeynep Ayla, ${ }^{1}$ Christopher P. Nicholas, ${ }^{2}$ Diwakar Shukla, ${ }^{1}$ and David W. Flaherty ${ }^{1, *}$

${ }^{1}$ Department of Chemical and Biomolecular Engineering, University of Illinois at UrbanaChampaign, Urbana, IL 61802

${ }^{2}$ Exploratory Materials and Catalysis Research, Honeywell UOP, Des Plaines, IL 60017

*Corresponding Author: dwflhrty@illinois.edu 


\begin{abstract}
Solvent structures that surround active sites reorganize during catalysis and influence the stability of surface intermediates. Within the pores of a zeolite, $\mathrm{H}_{2} \mathrm{O}$ molecules form hydrogen-bonded structures that differ significantly from bulk $\mathrm{H}_{2} \mathrm{O}$. Spectroscopic measurements and molecular dynamics simulations show that $\mathrm{H}_{2} \mathrm{O}$ molecules form bulk-like three-dimensional structures within $1.3 \mathrm{~nm}$ cages, while $\mathrm{H}_{2} \mathrm{O}$ molecules coalesce into oligomeric one-dimensional chains distributed throughout zeolite frameworks when the pore diameter is smaller than $0.65 \mathrm{~nm}$. The differences between the motifs of these solvent structures provide opportunities to manipulate enthalpy-entropy compensation relationships and significantly increase rates of catalytic turnover events. Here, we explain how the reorganization of these pore size-dependent $\mathrm{H}_{2} \mathrm{O}$ structures during alkene epoxidation catalysis gives rise to entropy gains that increase turnover rates by up to 400 -fold. Collectively, this work shows how solvent molecules form discrete structures with highly correlated motion within microporous environments, and that the reorganization of these structures may be controlled to confer stability to reactive intermediates.
\end{abstract}




\section{Introduction:}

Solid-liquid interfaces possess all of the complexities of gas-solid interfaces; yet, the presence of solvating molecules introduces specific interactions among solvent molecules, solid surfaces, and reactive species that greatly affect the efficacy of a material as a catalyst or adsorbent. ${ }^{1-3}$ These complex, manybody interactions among solvent molecules and surface species couple inherently fast electron-transfer processes with slower long-range changes in the structure of the solvation shells that cumulatively affect the free energies of adsorption, activation, and reaction. Catalytic reactions within zeolites are especially sensitive to these effects, because the pores that confine active sites possess dimensions similar to the solvation shells of surface intermediates $(0.5-2 \mathrm{~nm}) .{ }^{4}$ Consequently, the topology and polarity of these pores induce significant changes in the structure and dynamics of the solvent molecules. ${ }^{5-9}$

Water $\left(\mathrm{H}_{2} \mathrm{O}\right)$ molecules within microporous environments form intricate structures through hydrogen bonds (HB) that impact the stability of adsorbates, intrapore diffusion coefficients, and surface reactions. Decades of work have shown that HBs among aqueous solvents and polar surfaces can affect the adsorption of alcohols within microporous solids, ${ }^{8-14}$ transport of $\mathrm{H}_{2} \mathrm{O}$ through carbon nanotubes, ${ }^{15-17}$ and the stability of reactive surface intermediates within zeolites. ${ }^{5,6,18-21}$ The role of confined water in biocatalysis, however, is more clearly understood due to the successful characterization of water structures within the catalytic clefts of enzymes. ${ }^{22-24}$ This insight provided opportunities to design optimal solvents and mutations that improve enzymatic performance. ${ }^{25-28}$ Such knowledge does not yet exist for catalytic reactions within solvent-filled pores of zeolites despite the ubiquity and industrial importance of these systems. ${ }^{29,30}$ In zeolite catalysts, silanol defects $\left((\mathrm{SiOH})_{\mathrm{x}}\right)$ and other $\mathrm{HB}$ donors stabilize $\mathrm{H}_{2} \mathrm{O}$ molecules within pores and near active sites. ${ }^{8,931,32}$ These $\mathrm{H}_{2} \mathrm{O}$ molecules form structures that depend on the topology of the zeolite and must reorganize in response to nearby catalytic events. For example, rates of 1-octene epoxidation increase 100 -fold when the density of $(\mathrm{SiOH})_{\mathrm{x}}$ increases from 0 to $\sim 5$ per unit cell within TiBEA, ${ }^{5}$ because the disruption of $\mathrm{H}_{2} \mathrm{O}$ clusters near Ti active sites greatly increases the entropy of the system. ${ }^{5,6}$ Conversely, glucose isomerization rates are $5-50$-fold greater in hydrophobic Ti- and Sn-BEA than hydrophilic analogues, because $\mathrm{H}_{2} \mathrm{O}$ co-localized near active sites forms $\mathrm{HB}$ structures with glucose and decreases the entropy of relevant transition states. ${ }^{20,33-35}$ In both of these examples, the dependence of epoxidation and glucose isomerization turnover rates on $(\mathrm{SiOH})_{\mathrm{x}}$ density reflect changes in the thermodynamic stability of transition states via the $\mathrm{H}_{2} \mathrm{O}$ structures occluded within the BEA pores. Consequently, the catalysis community recognizes that $\mathrm{H}_{2} \mathrm{O}$ structures that form within zeolites greatly affects the stability of surface intermediates. However, we lack a quantitative understanding for how the physicochemical properties of these $\mathrm{H}_{2} \mathrm{O}$ structures depends on the shape and size of the surrounding pore and, more generally, how these structures impact catalysis at solid-liquid interfaces.

Here, we characterize the structure of $\mathrm{H}_{2} \mathrm{O}$ contained within FAU, BEA, MFI, and CDO zeolites of varying silanol density using a combination of spectroscopic and kinetic methods and molecular dynamics simulations to illustrate the impact of pore topology and polarity. We elucidate how the reorganization of $\mathrm{H}_{2} \mathrm{O}$ solvent structures during epoxidation catalysis changes the free energies of reactive surface intermediates and facilitates reaction. $\mathrm{H}_{2} \mathrm{O}$ molecules form bulk-like structures within the $1.3 \mathrm{~nm}$ supercages of FAU zeolites. In contrast, $\mathrm{H}_{2} \mathrm{O}$ molecules coalesce into confined one-dimensional chains as the characteristic pore dimension decreases from the 1.3 to $0.45 \mathrm{~nm}$. Kinetic measurements of 1-alkene epoxidation over Ti-containing zeolites provide a complementary method to evince the effects of confined $\mathrm{H}_{2} \mathrm{O}$ molecules on the stability of species relevant for catalysis. Confined $\mathrm{H}_{2} \mathrm{O}$ molecules dynamically restructure to accommodate the formation of reactive intermediates, and these processes produce large differences (greater than 400-fold) in measured epoxidation rates. Collectively, these data and interpretations demonstrate how solvent molecules may form complex structures within confining 
environments, whose reorganization during catalysis may have a large impact on the stability of surface intermediates and measured rates and selectivities. These phenomena likely extend to other classes of microporous materials (e.g., carbon nanotubes, metal-organic frameworks, silico-alumino phosphates) and polar and protic solvents (e.g., alcohols, lactones), which present new opportunities to understand and engineer solid-liquid interfaces. 


\section{Results and Discussion:}

\section{Spectroscopic and Computational Characterization of $\mathrm{H}_{2} \mathrm{O}$ Structures within Varying Zeolite Pore Topologies}

The presence of silanol defects $\left((\mathrm{SiOH})_{x}\right.$; i.e., the hydrophility of a material) stabilizes $\mathrm{H}_{2} \mathrm{O}$ within zeolite pores and impacts adsorption energies for $\mathrm{H}_{2} \mathrm{O}$ within BEA and MFI zeolites. . $7,70,14,19,20,31,36-38^{\text {The }}$ literature, however, lacks an understanding for how the structures that $\mathrm{H}_{2} \mathrm{O}$ forms depends on the combination of zeolite topology and $(\mathrm{SiOH})_{\mathrm{x}}$ densities. Moreover, the thermochemical properties of these $\mathrm{H}_{2} \mathrm{O}$ structures will likely exhibit a complex dependence on the pore diameter and $(\mathrm{SiOH})_{\mathrm{x}}$ density, because the importance of $\mathrm{SiOH}$ functions may change as $\mathrm{H}_{2} \mathrm{O}$ loses opportunities to hydrogen bond via spatial constraints. To understand the role of $\mathrm{SiOH}$ functions on stabilizing $\mathrm{H}_{2} \mathrm{O}$ structures within zeolite pores, we measured in situ infrared (IR) spectra and conducted molecular dynamics (MD) simulations of the $\mathrm{H}_{2} \mathrm{O}$ present within both hydrophilic and hydrophobic variants of the Ti-zeolite frameworks when these materials are immersed in liquid water.

Titanium substituted zeolites with the FAU (1.3 nm supercages), BEA ( $0.65 \mathrm{~nm}$ pores), MFI ( 0.55 $\mathrm{nm}$ pores) frameworks and siliceous CDO $(0.45 \mathrm{~nm}$ pores $)$ were synthesized through post-synthetic modification $^{5,39,40}$ or hydrothermal synthesis ${ }^{19}$ to prepare materials with a range of controlled topologies (e.g., 2D pore networks, 3D supercages), mean pore dimensions $(0.45-1.3 \mathrm{~nm})$, and densities of $(\mathrm{SiOH})_{\mathrm{x}}$. Here, we make comparisons primarily among materials that contain the greatest and lowest densities of $(\mathrm{SiOH})_{\mathrm{x}}$ (i.e., the most hydrophilic and hydrophobic samples). Materials named Ti-zeolite-OH are the variant of the framework that contains the greatest densities of $(\mathrm{SiOH})_{x}$ (i.e., are the most hydrophilic), while those denoted as Ti-zeolite-F were synthesized to contain low densities of $(\mathrm{SiOH})_{\mathrm{x}}$ (i.e., are hydrophobic). The MD simulations of hydrophilic materials involved structures containing $\sim 5(\mathrm{SiOH})_{4}$ defects per unit cell place at non-adjacent tetrahedral sites but otherwise located randomly. The same $(\mathrm{SiOH})_{4}$ density was used in simulations of Si-CDO-OH samples to facilitate equitable comparisons, although this material contains fewer $(\mathrm{SiOH})_{x}$ groups than other Ti-zeolite-OH samples (Fig. S3). MD simulations of hydrophobic structures made use of pristine frameworks with zero $(\mathrm{SiOH})_{x}$ groups. Detailed characterization of all materials, the specifics of experimental methods, spectral and rate analysis methods, and computational methods are in the supporting information.

Bulk $\mathrm{H}_{2} \mathrm{O}$ differs structurally from $\mathrm{H}_{2} \mathrm{O}$ stabilized within the pores of a zeolite. Figure 1 shows IR spectra of bulk water (Fig. 1a) and of water within Ti-FAU-OH (Fig. 1b), Ti-BEA-OH (Fig. 1c), Ti-MFI$\mathrm{OH}$ (Fig. 1d), and Si-CDO-OH (Fig. 1e) at $313 \mathrm{~K}$. These spectra show distinct features between $2750-$ $3750 \mathrm{~cm}^{-1}$ that reflect $v(\mathrm{O}-\mathrm{H})$ of $\mathrm{H}_{2} \mathrm{O}$ molecules within chemically distinguishable bonding configurations. Experimental IR, ${ }^{41}$ Raman, ${ }^{42}$ and sum-frequency generation ${ }^{43}$ spectroscopies and computational predictions ${ }^{44}$ demonstrate that condensed-phase $\mathrm{H}_{2} \mathrm{O}$ molecules possess five specific hydrogen-bonding configurations (top of Fig. 1; Table S2) that include "free" $\mathrm{H}_{2} \mathrm{O}$ that lacks $\mathrm{HB}$ (Free; $23636 \mathrm{~cm}^{-1}$ ), $\mathrm{H}_{2} \mathrm{O}$ that donates two and accepts one $\mathrm{HB}\left(\mathrm{DDA} ; \sim 3570 \mathrm{~cm}^{-1}\right.$ ), $\mathrm{H}_{2} \mathrm{O}$ that donates one and accepts one $\mathrm{HB}$ (DA; 3470 $\mathrm{cm}^{-1}$ ), $\mathrm{H}_{2} \mathrm{O}$ that both donates and accepts two $\mathrm{HB}$ (DDAA; $3320 \mathrm{~cm}^{-1}$ ), and $\mathrm{H}_{2} \mathrm{O}$ that donates one and accepts two HB (DAA; $3040 \mathrm{~cm}^{-1}$ ). The vibrational spectra of bulk $\mathrm{H}_{2} \mathrm{O}$ (Fig. 1a) shows that $v(\mathrm{O}-\mathrm{H})$ of $\mathrm{H}_{2} \mathrm{O}$ in a DDAA bonding configuration dominates the measured spectra, which agrees with prior reports. ${ }^{42,43}$ Within the bulk-fluid phase, $\mathrm{H}_{2} \mathrm{O}$ molecules form dynamic three-dimensional hydrogen bonding structures described well by our MD simulations of TIP5P $\mathrm{H}_{2} \mathrm{O}$ (Fig. 1f). 


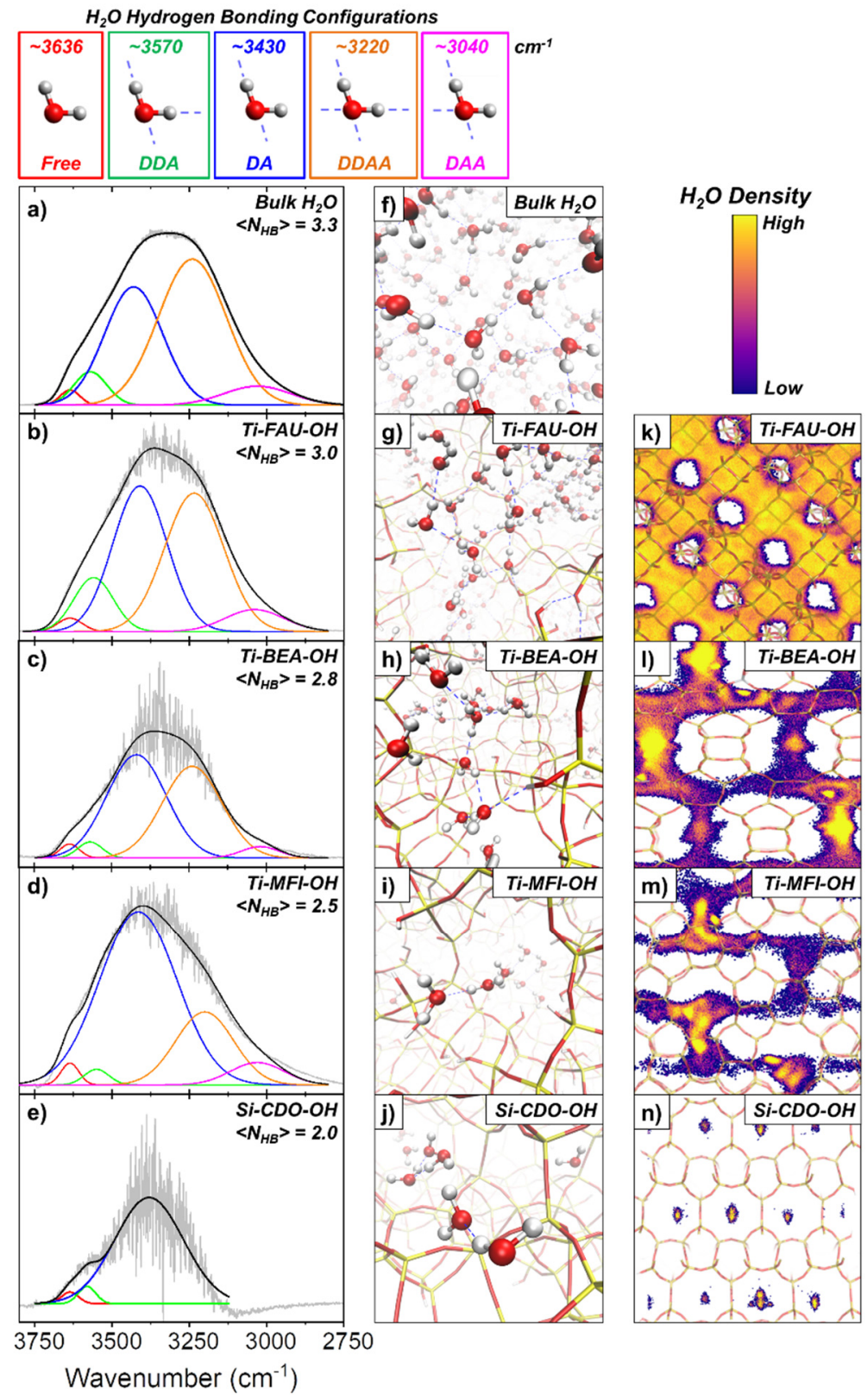

Figure 1. Infrared spectroscopic characterization and molecular dynamics simulations of $\mathrm{H}_{2} \mathrm{O}$ within the bulk fluid phase and confined within pores of hydrophilic zeolites. a - e, Infrared spectra (gray) of $\mathrm{H}_{2} \mathrm{O}$ over a $\mathrm{ZnSe}$ internal reflection element (bulk $\mathrm{H}_{2} \mathrm{O}$; a) within the pores of Ti-FAU-OH (b), Ti-BEA$\mathrm{OH}(\mathbf{c})$, Ti-MFI-OH (d), or Si-CDO-OH (e) at $313 \mathrm{~K} . \mathbf{f}-\mathbf{j}$, Snapshots of the MD simulations of $\mathrm{H}_{2} \mathrm{O}$ within the bulk fluid phase (f) or within the pores Ti-FAU-OH (g), Ti-BEA-OH (h), Ti-MFI-OH (i), or Si-CDO$\mathrm{OH}(\mathbf{j})$ that were constructed to contain $5(\mathrm{SiOH})_{4}$ per unit cell at $313 \mathrm{~K}$. $\mathbf{k}-\mathbf{n}$, Two-dimensional heat map projections of the position of $\mathrm{H}_{2} \mathrm{O}$ molecules sampled during a $1 \mu \mathrm{s}$ MD simulation within Ti-FAU-OH (k), Ti-BEA-OH (l), Ti-MFI-OH (m), or Si-CDO-OH (n) at $313 \mathrm{~K}$. The time-averaged spatial distribution of $\mathrm{H}_{2} \mathrm{O}$ molecules is colored from low (purple) to high (yellow). Vibrational spectra in a-e were fit using up to five gaussian distributions to represent $\mathrm{v}(\mathrm{O}-\mathrm{H})$ of $\mathrm{H}_{2} \mathrm{O}$ molecules that exist in one of five color-coded hydrogen-bonding configurations, shown visually above $\mathbf{a}-\mathbf{e}$; cumulative fits are shown in black. The dashed lines in $\mathbf{f}-\mathbf{j}$ represent hydrogen bonds between $\mathrm{H}_{2} \mathrm{O}$ molecules. Heat maps in k-n are viewed down the b-, b-, b-, and c-axes of the Ti-FAU, Ti-BEA, Ti-MFI, and Si-CDO crystals, respectively. 
IR spectra of $\mathrm{H}_{2} \mathrm{O}$ within Ti-FAU-OH (Fig. 1b) show that $\mathrm{H}_{2} \mathrm{O}$ within the $1.3 \mathrm{~nm}$ supercages of hydrophilic FAU and of hydrophobic (pristine) Ti-FAU-F (Fig. S4a) appear largely similar and possess lineshapes that resemble bulk $\mathrm{H}_{2} \mathrm{O} . \mathrm{H}_{2} \mathrm{O}$ within these supercages possess the spatial freedom to form threedimensional structures (Figs. $1 \mathrm{~g}$ and $\mathrm{S} 4 \mathrm{~d}$ ); yet, a fraction of $\mathrm{H}_{2} \mathrm{O}$ molecules adopt a DDAA configuration by simultaneously forming $\mathrm{HBs}$ with both $\mathrm{SiOH}$ defects and other $\mathrm{H}_{2} \mathrm{O}$. These differences are reflected between the time-averaged spatial distributions of $\mathrm{H}_{2} \mathrm{O}$ in Ti-FAU-F and Ti-FAU-OH: the former exhibits a regular and well-defined boundary (Fig. S4g) whereas that latter contains irregularities caused by the attractive interactions between $\mathrm{H}_{2} \mathrm{O}$ and randomly sited silanol groups within the FAU structure (Fig. 1k). Within Ti-BEA-OH and Ti-MFI-OH, $\mathrm{H}_{2} \mathrm{O}$ molecules within the DA configuration account for a much larger fraction of the vibrational spectra (Figs. 1c and 1d). These hydrophilic materials, however, also stabilize greater numbers of DDAA $\mathrm{H}_{2} \mathrm{O}$ molecules than the analogous Ti-BEA-F (Fig. S4b) and Ti-MFIF (Fig. S4c) materials, because $\mathrm{H}_{2} \mathrm{O}$ hydrogen bonds with $(\mathrm{SiOH})_{x}$ defects at the pore walls. Within TiBEA-OH, $\mathrm{H}_{2} \mathrm{O}$ molecules with the DDAA configuration congregate at intersections between pores (Figs. $1 \mathrm{~h}, 1 \mathrm{l}, \mathrm{S} 4 \mathrm{~d}$, and $\mathrm{S} 4 \mathrm{~g}$ ) or at mesoporous grain-boundary defects. ${ }^{45}$ In comparison to frameworks with larger pore diameter, $\mathrm{H}_{2} \mathrm{O}$ molecules within Si-CDO-OH (Fig. 1e) largely exist within the DA hydrogen bonding configuration. Collectively, the combined interpretation of these results suggest that $\mathrm{H}_{2} \mathrm{O}$ molecules form solvent structures that, on average, possess fewer hydrogen bonds per $\mathrm{H}_{2} \mathrm{O}$ molecule and different hydrogen bonding partners as the characteristic diameter of the surrounding pore decreases.

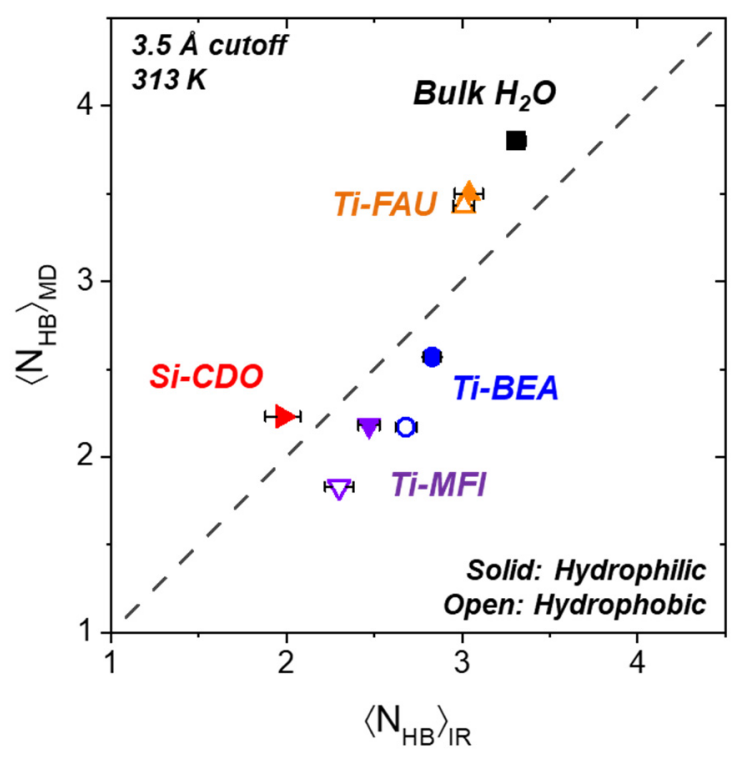

Figure 2. Comparisons between the average number of hydrogen bonds per water molecule determined by MD simulations and measured by infrared spectroscopy. Average numbers of hydrogen bonds per $\mathrm{H}_{2} \mathrm{O}$ molecule calculated from $\mathrm{MD}$ simulations $\left(<\mathrm{N}_{\mathrm{HB}}>\mathrm{MD}\right)$ compared against those estimated from infrared spectra of $\mathrm{H}_{2} \mathrm{O}\left(<\mathrm{N}_{\mathrm{HB}}>_{\mathrm{IR}}\right)$ within the bulk fluid phase (घ), Ti-FAU $(\Delta)$, Ti-BEA $(\bullet)$, Ti-MFI $(\nabla)$, or Si-CDO $(\nabla)$ at $313 \mathrm{~K}$. Solid symbols correspond to MD simulations of hydrophilic zeolite frameworks with $5(\mathrm{SiOH})_{4}\left(\right.$ unit cell) ${ }^{-1}$ or the most hydrophilic zeolite samples (i.e., Si-CDO-OH, Ti-MFI$\mathrm{OH}$, Ti-BEA-OH, Ti-FAU-OH). Open symbols correspond to MD simulations of pristine zeolite frameworks containing no framework defects or the most hydrophobic zeolite samples (i.e., Ti-MFI-F, TiBEA-F, Ti-FAU-F). A distance cutoff of $3.5 \AA$ A between the hydrogen bond donor or acceptor atoms was used to calculate the number of hydrogen bonds per $\mathrm{H}_{2} \mathrm{O}$ molecule during the MD simulations, and these numbers include bonds between $\mathrm{H}_{2} \mathrm{O}$ molecules and between $\mathrm{H}_{2} \mathrm{O}$ and surface silanol groups. The dashed line represents parity. 
To further investigate how topology and surface chemistry of the pores affect the structure of $\mathrm{H}_{2} \mathrm{O}$, we compared the average number of HBs calculated from vibrational spectra $\left.\left(<\mathrm{N}_{\mathrm{HB}}\right\rangle_{\mathrm{IR}}\right)$ to those observed during the $\mathrm{MD}$ simulation $\left(<\mathrm{N}_{\mathrm{HB}}>\mathrm{MD}\right)$. The experimental measurements and $\mathrm{MD}$ simulations show consistent differences among hydrophobic (Ti-zeolite-F) and hydrophilic (Ti-zeolite-OH) zeolite structures. The average number of HB decreases uniformly with the mean diameter of the zeolite pore and with the number of hydrogen bond donating residues on the pore walls. Figure 2 establishes these trends via the level of parity between values of $\left\langle\mathrm{N}_{\mathrm{HB}}>_{\mathrm{IR}}\right.$ and $\left\langle\mathrm{N}_{\mathrm{HB}}>\mathrm{MD}\right.$ across all materials examined. $\mathrm{H}_{2} \mathrm{O}$ within the bulk fluid phase and Ti-FAU possess an average of $3-3.6 \mathrm{HBs}$ irrespective of density of $(\mathrm{SiOH})_{4}$. The average number of hydrogen bonds decreases monotonically towards an average value of $\sim 2$ as the characteristic pore diameter decreases across the series of Ti-BEA, Ti-MFI, and Si-CDO, because these sub-nanometer siloxane pores do not permit three-dimensional $\mathrm{HB}$ networks among $\mathrm{H}_{2} \mathrm{O}$ molecules. Further, values of $<\mathrm{N}_{\mathrm{HB}}>_{\mathrm{IR}}$ and $<\mathrm{N}_{\mathrm{HB}}>_{\mathrm{MD}}$ agree closely with prior reports, where MD simulations of defect-free Si-FAU, ${ }^{46} \mathrm{Si}-$ MFI, ${ }^{46,47}$ and $\mathrm{H}^{+}$-form Al-BEA ${ }^{48}$ show that, on average, $\mathrm{H}_{2} \mathrm{O}$ within the FAU, BEA, and MFI frameworks possess $\sim 3, \sim 2.7$, and $\sim 2 \mathrm{HBs}$ per $\mathrm{H}_{2} \mathrm{O}$ molecule, respectively.

Analysis of the MD simulations (validated by comparisons to experimental results, Figure 2) provide insight to the structural properties of $\mathrm{H}_{2} \mathrm{O}$ within the zeolite frameworks and its dependence on interactions among $\mathrm{H}_{2} \mathrm{O}$ molecules, $(\mathrm{SiOH})_{\mathrm{x}}$ defects, and the siloxane pore walls. Ti-FAU-F, on average, stabilizes $\sim 118 \mathrm{H}_{2} \mathrm{O}$ molecules per unit cell, while Ti-BEA-F contains an average of $\sim 5 \mathrm{H}_{2} \mathrm{O}$ molecules per unit cell (Table S4). In comparison, Ti-MFI-F and stabilizes only $\sim 2 \mathrm{H}_{2} \mathrm{O}$ molecules per unit cell. Strikingly, $\mathrm{H}_{2} \mathrm{O}$ molecules do not enter the Si-CDO-F structure over throughout the course of our $1 \mu \mathrm{s}$ MD simulations. These low uptakes are qualitatively consistent with reported $\mathrm{H}_{2} \mathrm{O}$ uptakes into these hydrophobic frameworks. The MD simulations indicate that the numbers of $\mathrm{H}_{2} \mathrm{O}$ molecules stabilized within hydrophilic variants of Ti-FAU, -BEA, and -MFI differ only slightly from values in hydrophobic samples (Table S3) but Si-CDO-OH possesses $\sim 2 \mathrm{H}_{2} \mathrm{O}$ per unit cell. Given the small change in the overall volume per unit cell between hydrophilic and hydrophobic samples of the zeolites, the number of water molecules per unit cell for these variants are expected to be similar. However, the hydrophilic samples preferentially stabilize $\mathrm{H}_{2} \mathrm{O}$ molecules near defects and increase the local density of water. Conversely, the hydrophobic samples containing similar number of water molecules would exhibit higher fluctuations in the water molecule positions in absence of any stabilizing interaction with the pore. ${ }^{49}$ Together, these data suggest $\mathrm{H}_{2} \mathrm{O}$ completely fills the supercages of FAU but does not fully occupy the sub-nanometer channels of BEA, MFI, and CDO. Instead, $\mathrm{H}_{2} \mathrm{O}$ molecules coalesce into discrete structures distributed throughout these porous architectures.

Speciation of the $\mathrm{HBs}$ to $\mathrm{H}_{2} \mathrm{O}$ molecules within the MD simulations reveal that the percentage of $\mathrm{HBs}$ that $\mathrm{H}_{2} \mathrm{O}$ forms with surface functions (i.e., $\mathrm{SiOH}$ or $\mathrm{Si}-\mathrm{O}-\mathrm{Si}$ linkages) increases as characteristic pore diameters decrease and $(\mathrm{SiOH})_{4}$ density increases (Tables $\mathrm{S} 3$ and $\mathrm{S} 4$ ). $\mathrm{HBs}$ between $\mathrm{H}_{2} \mathrm{O}$ molecules and $\mathrm{SiOH}$ functions account for $1 \%$ and $6 \%$ of all $\mathrm{HB}$ interactions within Ti-FAU-F and Ti-FAU-OH, respectively. In contrast, much larger percentages of $\mathrm{HBs}$ involve $\mathrm{SiOH}$ groups within Ti-BEA-OH (16\%), Ti-MFI-OH (35\%), and Si-CDO-OH (60\%). Further, these trends and further analysis indicate $\mathrm{H}_{2} \mathrm{O}$ molecules form one-dimensional chains (primarily dimers through tetramers) with multiple points of interactions with $(\mathrm{SiOH})_{x}$ defects within $\mathrm{BEA}, \mathrm{MFI}$, and $\mathrm{CDO}$ structures. The prevalence and structure of these oligomeric chains agrees with IR spectra that show large fractions of $\mathrm{H}_{2} \mathrm{O}$ exists in DA hydrogenbonding configurations inside Ti-BEA, Ti-MFI, and Si-CDO-OH (Figs. 1 and S4). In summary, concurrent interpretation of the infrared spectra of $v(\mathrm{O}-\mathrm{H})$, parity between $\left\langle\mathrm{N}_{\mathrm{HB}}\right\rangle_{\mathrm{IR}}$ and $\left\langle\mathrm{N}_{\mathrm{HB}}\right\rangle_{\mathrm{MD}}$, and simulated distributions of $\mathrm{HB}$ configurations strongly suggest that $\mathrm{H}_{2} \mathrm{O}$ forms three-dimensional bulk-like structures within FAU but largely one-dimensional oligomers within BEA, MFI, and CDO, the density of which should vary with the activity of liquid $\mathrm{H}_{2} \mathrm{O}$ and density of silanol groups. 
As a consequence of these interactions, the molecular motion of $\mathrm{H}_{2} \mathrm{O}$ molecules are strongly correlated in ways that depend on the size and surface chemistry of the surrounding pores. Although TiBEA, Ti-MFI, and Si-CDO zeolites all stabilize $\mathrm{H}_{2} \mathrm{O}$ molecules as oligomeric chains, the translational motion of $\mathrm{H}_{2} \mathrm{O}$ within the pores differs significantly among these frameworks and with the presence of $(\mathrm{SiOH})_{x}$. Analysis of time-averaged spatial distributions from MD simulations (Section S4.2) show that $\mathrm{H}_{2} \mathrm{O}$ molecules can radially translate up to $\sim 2.2 \AA$ from the centerline of the Ti-BEA-F pores but only $\sim 1$ and $0.6 \AA$ from the center of pores within Ti-MFI-F and Si-CDO-OH, respectively. Moreover, the space accessed by $\mathrm{H}_{2} \mathrm{O}$ molecules increases significantly with the addition of $(\mathrm{SiOH})_{4}$. These changes in spatial and structural confinement of the chains of $\mathrm{H}_{2} \mathrm{O}$ molecules within these zeolites significantly affects the thermodynamic properties of these solvent structures (vide infra).
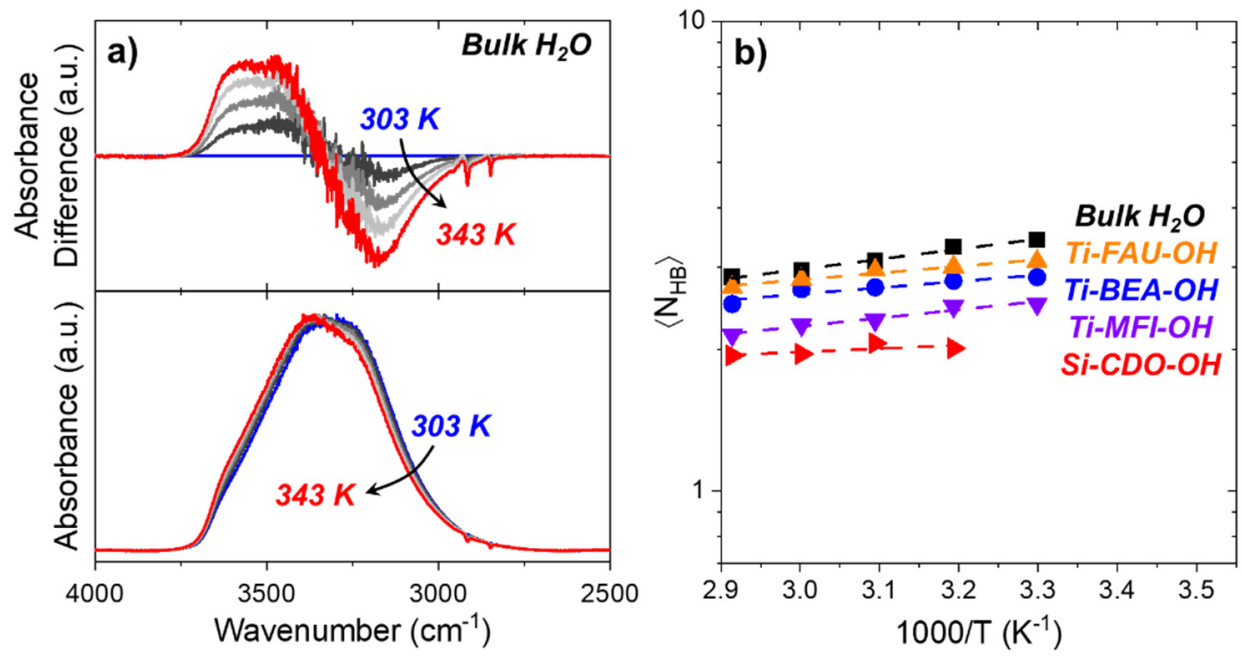

Figure 3. Temperature dependent infrared spectra of intrapore $\mathrm{H}_{2} \mathrm{O}$ molecules to quantify strength of hydrogen bonds. a, Infrared spectra of bulk $\mathrm{H}_{2} \mathrm{O}$ between $303 \mathrm{~K}$ (blue) and 343 (red) $\mathrm{K}$ in increments of $10 \mathrm{~K}$ (bottom) and difference between a given spectra to that collected at $303 \mathrm{~K}$ (top). $\mathbf{b}$, The average number of hydrogen bonds $\left(\langle N\rangle_{H B}\right.$ ) for bulk $\mathrm{H}_{2} \mathrm{O}$ (black $\mathbf{m}$ ), Ti-FAU-OH (orange $\Delta$ ), Ti-BEA-OH (blue $\bullet$ ), Ti-MFI-OH (purple $\boldsymbol{\nabla}$ ), and Si-CDO-OH (red $>$ ) as a function of inverse temperature. All IR spectra within a (top) are normalized to the most intense $v(\mathrm{O}-\mathrm{H})$ feature. The dashed lines in $\mathbf{b}$ represent fits of the van't Hoff equation, whose slopes are proportional to the enthalpy change associated with breaking a hydrogen bond between $\mathrm{H}_{2} \mathrm{O}$ molecules in a given environment $\left(\Delta \mathrm{H}_{<\mathrm{HB}>}\right)$.

The thermodynamic stability of hydrogen bonds between $\mathrm{H}_{2} \mathrm{O}$ molecules entrained within zeolites depend strongly on the shape and size of the solvent cluster. ${ }^{5,6,50,51}$ We measured IR spectra of $\mathrm{H}_{2} \mathrm{O}$ molecules in the bulk-fluid phase and within pores of hydrophilic and hydrophobic zeolite frameworks (FAU, BEA, MFI, CDO) as functions of temperature to interrogate the changes in enthalpy and entropy that result from the disruption of $\mathrm{HBs}$ within $\mathrm{H}_{2} \mathrm{O}$ structures in these distinct environments. Figure 3a shows IR spectra of bulk $\mathrm{H}_{2} \mathrm{O}$ as a function of temperature $(303-343 \mathrm{~K})$ possess $v(\mathrm{O}-\mathrm{H})$ that systematically shift to higher wavenumbers with increasing temperature and shows a clear isosbestic point at $3345 \mathrm{~cm}^{-1}$, which agrees with previously reported Raman ${ }^{42,52}$ and infrared ${ }^{53}$ spectra of $\mathrm{H}_{2} \mathrm{O}$. The blue shift in $v(\mathrm{O}-\mathrm{H})$ with temperature reflects a change in the populations of $\mathrm{H}_{2} \mathrm{O}$ that exist in one of the five hydrogen bonding configurations (vide supra). The change in enthalpy associated with disrupting a single hydrogen bond 
among $\mathrm{H}_{2} \mathrm{O}$ molecules $\left(\Delta \mathrm{H}_{<\mathrm{HB}}\right)$ within the different pore environments was quantified via van't Hoff analysis of the changes in $\langle N\rangle_{H B}{ }^{42}$ In this analysis, the molar extinction coefficients for $v(\mathrm{O}-\mathrm{H})$ of $\mathrm{H}_{2} \mathrm{O}$ within the various HB arrangements are assumed to be the same. The enthalpy change associated with disrupting a $\mathrm{H}_{2} \mathrm{O}$ molecule $\left(\Delta \mathrm{H}_{\mathrm{HB}}\right)$ is then determined by multiplying $\Delta \mathrm{H}_{<\mathrm{HB}}>$ by $\langle N\rangle_{H B}$, which describes the change in enthalpy associated with perturbing the average $\mathrm{H}_{2} \mathrm{O}$ molecule within a given environment (Section S2.3.1). The corresponding change in entropy due to breaking a hydrogen bond $\left(\Delta \mathrm{S}_{\mathrm{HB}}\right)$ was determined using statistical mechanics (i.e., comparing the populations of $\mathrm{H}_{2} \mathrm{O}$ in the varying bonding configurations; Section S2.3.1). ${ }^{54}$

Table 1. Average number of hydrogen bonds $\left(\langle N\rangle_{H B}\right)$ measured via infrared spectroscopy at $313 \mathrm{~K}$, changes in enthalpy $\left(\Delta \mathrm{H}_{\mathrm{HB}}\right)$ and entropy $\left(\Delta \mathrm{S}_{\mathrm{HB}}\right)$ for disrupting the hydrogen bonds between $\mathrm{H}_{2} \mathrm{O}$ molecules, and the change in enthalpy $\left(\Delta \mathrm{H}_{<\mathrm{HB}}>\right)$ and entropy $\left(\Delta \mathrm{S}_{<\mathrm{HB}}>\right)$ for cleaving a single hydrogen bond between $\mathrm{H}_{2} \mathrm{O}$ molecules within $\mathrm{H}_{2} \mathrm{O}$ confined within voids of the zeolite pores with the greatest and lowest densities of $(\mathrm{SiOH})_{x}$ for each framework.

\begin{tabular}{|c|c|c|c|c|c|}
\hline $\begin{array}{c}\text { Confining } \\
\text { Environment }\end{array}$ & $\begin{array}{c}\langle N\rangle_{H B} \\
(\mathrm{~mol} \mathrm{HB})\left(\mathrm{mol} \mathrm{H}_{2} \mathrm{O}\right)^{-1}\end{array}$ & $\begin{array}{c}\Delta H_{H B} \\
\left(\mathrm{~kJ}\left(\mathrm{~mol} \mathrm{H}_{2} \mathrm{O}\right)^{-1}\right)\end{array}$ & $\begin{array}{c}\Delta H_{<H B>} \\
\left(\mathrm{kJ}(\mathrm{mol} \mathrm{HB})^{-1}\right)\end{array}$ & $\begin{array}{c}\Delta S_{H B} \\
\left(\mathrm{~J}\left(\mathrm{~mol} \mathrm{H}_{2} \mathrm{O}\right)^{-1} \mathrm{~K}^{-1}\right)\end{array}$ & $\begin{array}{c}\Delta S_{<H B>} \\
\left(\mathrm{J}(\mathrm{mol} \mathrm{HB})^{-1} \mathrm{~K}^{-1}\right)\end{array}$ \\
\hline Bulk $\mathrm{H}_{2} \mathrm{O}$ & 3.3 & $10 \pm 3$ & $3 \pm 1$ & $22 \pm 4$ & $7 \pm 1$ \\
\hline Ti-FAU-OH & 3.0 & $9 \pm 2$ & $3 \pm 1$ & $25 \pm 5$ & $8 \pm 1$ \\
\hline Ti-FAU-F & 3.0 & $9 \pm 3$ & $3 \pm 1$ & $27 \pm 4$ & $9 \pm 1$ \\
\hline Ti-BEA-OH & 2.8 & $6 \pm 2$ & $2 \pm 1$ & $41 \pm 6$ & $14 \pm 2$ \\
\hline Ti-BEA-F & 2.7 & $6 \pm 2$ & $2 \pm 1$ & $48 \pm 5$ & $18 \pm 2$ \\
\hline Ti-MFI-OH & 2.5 & $5 \pm 2$ & $2 \pm 1$ & $53 \pm 6$ & $21 \pm 3$ \\
\hline Ti-MFI-F & 2.3 & $5 \pm 1$ & $2 \pm 1$ & $60 \pm 5$ & $30 \pm 2$ \\
\hline Si-CDO-OH & 2.0 & $1 \pm 2^{\mathrm{a}}$ & $0 \pm 2^{\mathrm{a}}$ & $5 \pm 9^{\mathrm{a}}$ & $3 \pm 4^{\mathrm{a}}$ \\
\hline
\end{tabular}

${ }^{a}$ IR spectra of $\mathrm{H}_{2} \mathrm{O}$ within $\mathrm{Si}-\mathrm{CDO}-\mathrm{OH}$ do not show significant changes with temperature ( $\left.313-343 \mathrm{~K}\right)$, which imply the number of $\mathrm{HB}$ to $\mathrm{H}_{2} \mathrm{O}$ remains constant

Within bulk $\mathrm{H}_{2} \mathrm{O}$, the rupture of hydrogen bonds of an average $\mathrm{H}_{2} \mathrm{O}$ molecule to form free $\mathrm{H}_{2} \mathrm{O}$ results in a change in enthalpy $\left(\Delta \mathrm{H}_{\mathrm{HB}}\right)$ of $10 \mathrm{~kJ}\left(\mathrm{~mol} \mathrm{H}_{2} \mathrm{O}\right)^{-1}$ and provides a concomitant increase in entropy of $22 \mathrm{~J}\left(\mathrm{~mol} \mathrm{H}_{2} \mathrm{O}\right)^{-1} \mathrm{~K}^{-1}\left(\Delta \mathrm{S}_{\mathrm{HB}}\right.$; Table 1$)$. These values agree with literature values for the changes in enthalpy $\left(\sim 10 \mathrm{~kJ} \mathrm{~mol}^{-1}\right)$ and entropy $\left(\sim 25 \mathrm{~J}\left(\mathrm{~mol} \mathrm{H}_{2} \mathrm{O}\right)^{-1} \mathrm{~K}^{-1}\right)$ associated with the disruption of hydrogen bonding interactions within bulk $\mathrm{H}_{2} \mathrm{O} .{ }^{55,56} \mathrm{H}_{2} \mathrm{O}$ within Ti-FAU form nearly three-dimensional structures that result in $\mathrm{H}_{2} \mathrm{O}$ molecules with $<\mathrm{N}_{\mathrm{HB}}>$ values only slightly less than that for bulk water $\left(<\mathrm{N}_{\mathrm{HB}}>=3.3\right)$. As a result, values of $\Delta \mathrm{H}_{\mathrm{HB}}$ for $\mathrm{H}_{2} \mathrm{O}$ entrained within Ti-FAU $\left(\sim 9 \pm 2 \mathrm{~kJ}\left(\mathrm{~mol} \mathrm{H}_{2} \mathrm{O}\right)^{-1}\right)$ resemble that for bulk $\mathrm{H}_{2} \mathrm{O}$. Within Ti-BEA and Ti-MFI, $\mathrm{H}_{2} \mathrm{O}$ appears to exist as oligomers (vide supra) that merge and gain additional $\mathrm{HB}$ at intersections within these three-dimensional pore networks, such that $\mathrm{H}_{2} \mathrm{O}$ molecules possess two to three hydrogen bonds, on average. Consequently, values of $\Delta \mathrm{H}_{\mathrm{HB}}$ within Ti-BEA and Ti-MFI ( $\sim 5 \mathrm{~kJ}$ (mol $\left.\mathrm{H}_{2} \mathrm{O}\right)^{-1}$ ) are approximately half the value of those found in Ti-FAU and bulk $\mathrm{H}_{2} \mathrm{O}$. Interestingly, the value of $<\mathrm{N}_{\mathrm{HB}}>$ for Si-CDO-OH is the lowest among all structures $\left(<\mathrm{N}_{\mathrm{HB}}>=2.0\right)$ and $\Delta \mathrm{H}_{\mathrm{HB}}$ approaches zero, because the vibrational spectra of $\mathrm{H}_{2} \mathrm{O}$ show negligible changes with increasing temperature. This behavior suggests that $\mathrm{H}_{2} \mathrm{O}$ oligomers within Si-CDO-OH access multiple configurations with similar energies (Section S2.4). We postulate that the disruption of individual $\mathrm{HB}$ between pairs of $\mathrm{H}_{2} \mathrm{O}$ molecules results in concomitant restructuring of the $\mathrm{H}_{2} \mathrm{O}$ oligomers to form $\mathrm{HB}$ with nearby $(\mathrm{SiOH})_{\mathrm{x}}$ functions, which maintains a constant average of two $\mathrm{HB}$ and gives nearly equivalent interaction energies. This interpretation seems consistent with values of $\Delta \mathrm{H}_{\mathrm{HB}}$ that do not depend on the density of $(\mathrm{SiOH})_{\mathrm{x}}$ within a given 
framework despite the significant fraction of $\mathrm{HB}$ observed between $\mathrm{H}_{2} \mathrm{O}$ and $(\mathrm{SiOH})_{4}$ in simulations (Tables S3 and S4). Comparisons among these measurements show that the intrinsic enthalpic stabilization afforded by a single hydrogen bond (i.e., values of $\Delta \mathrm{H}_{<\mathrm{HB}}>$ ) does not depend on the topology or defect density of a zeolite, however, the entropy gained when a hydrogen bond cleaves depends strongly on the remaining number of hydrogen bonds to the $\mathrm{H}_{2} \mathrm{O}$ molecule.

The disruption of $\mathrm{H}_{2} \mathrm{O}$ structures gives rise to an increase in entropy that reflects the increase in the number of accessible microstates of the system. Values of $\Delta \mathrm{S}_{\mathrm{HB}}$ within Ti-FAU are similar that of bulk $\mathrm{H}_{2} \mathrm{O}$, which reflects the three-dimensional $\mathrm{H}_{2} \mathrm{O}$ clusters $(\sim 1.3 \mathrm{~nm})$ that form within the supercages of FAU. $\Delta \mathrm{S}_{\mathrm{HB}}$ values within Ti-FAU do not depend on the density of $(\mathrm{SiOH})_{\mathrm{x}}$, likely because the HBs within these supercages primarily reflect bonds between $\mathrm{H}_{2} \mathrm{O}$ molecules, rather than with $(\mathrm{SiOH})_{\mathrm{x}}$ defects (Table $\mathrm{S} 3$ ). The disruption of $\mathrm{H}_{2} \mathrm{O}$ within Ti-MFI leads to $\Delta \mathrm{S}_{\mathrm{HB}}$ that are $\sim 12 \mathrm{~J} \mathrm{~mol}^{-1} \mathrm{~K}^{-1}$ greater than Ti-BEA. The greater values of $\Delta \mathrm{S}_{\mathrm{HB}}$ for $\mathrm{H}_{2} \mathrm{O}$ in $0.55 \mathrm{~nm}$ pores of Ti-MFI reflect lesser $<\mathrm{N}_{\mathrm{HB}}>$ compared to those in the $0.65 \mathrm{~nm}$ pores of Ti-BEA. Values of $\Delta \mathrm{S}_{\mathrm{HB}}$ also decrease slightly with $\left[(\mathrm{SiOH})_{\mathrm{x}}\right]$ for a given zeolite framework, which suggests that $(\mathrm{SiOH})_{x}$ defects provide a stabilizing interaction when $\mathrm{HB}$ among $\mathrm{H}_{2} \mathrm{O}$ molecules are disrupted. The differences of $\Delta \mathrm{S}_{\mathrm{HB}}$ among all these zeolite structures may be envisioned as cutting strands of a rope. Within bulk water and Ti-FAU, the ropes possess multiple strands that bind $\mathrm{H}_{2} \mathrm{O}$ molecules even when a single strand fails. In contrast, ropes within Ti-MFI, and to a lesser extent Ti-BEA, contain fewer strands and the loss of a single one may allow $\mathrm{H}_{2} \mathrm{O}$ molecules to break free. Si-CDO-OH differs considerably: measured values of $\Delta \mathrm{S}_{\mathrm{HB}}$ (and $\Delta \mathrm{H}_{\mathrm{HB}}$ ) are nearly zero because a $\mathrm{HB}$ between $\mathrm{H}_{2} \mathrm{O}$ and a silanol group replaces each $\mathrm{HB}$ lost between $\mathrm{H}_{2} \mathrm{O}$ molecules due to significant spatial confinement within these $0.45 \mathrm{~nm}$ pores.

Collectively, these data and interpretations show that $\mathrm{H}_{2} \mathrm{O}$ molecules coalesce into structures, whose shape and properties depend strongly on the topology of the surrounding pore and to a lesser degree on the $\left[(\mathrm{SiOH})_{x}\right]$. As the characteristic dimensions of the pores decrease, the $\mathrm{H}_{2} \mathrm{O}$ solvent structures lose the added stability conferred by forming $\mathrm{HB}$ with other $\mathrm{H}_{2} \mathrm{O}$ in more than one dimension and become motion among $\mathrm{H}_{2} \mathrm{O}$ molecules becomes increasingly correlated. ${ }^{57,58}$ Therefore, the enthalpic costs and entropic gains associated with breaking each HB depend on zeolite topology. These relationships between the enthalpy and entropy of creating and forming $\mathrm{HBs}$ with $\mathrm{H}_{2} \mathrm{O}$ molecules carries catalytic consequences that appear as differences in turnover rates and the stability of surface intermediates at solid-liquid interfaces, as we demonstrate below.

\section{Influence of $\mathrm{H}_{2} \mathrm{O}$ Structure and Reorganization on Liquid-Phase Epoxidation Catalysis}

Kinetic measurements for alkene epoxidation reactions with $\mathrm{H}_{2} \mathrm{O}_{2}$ provide an ideal method to examine the catalytic consequences of the structure and dynamics of intraporous $\mathrm{H}_{2} \mathrm{O}$, because these reactions exhibit rates that depend strongly on the density of $(\mathrm{SiOH})_{\mathrm{x}}{ }^{5,6}$ and size of the confining pore. ${ }^{18,39,40}$ Figure 4 shows rates of 1-alkene epoxidation are 10 - 400-fold greater in zeolites that contain significant densities of $(\mathrm{SiOH})_{x}$ (i.e., are hydrophilic) than the analogous structures with far fewer $(\mathrm{SiOH})_{\mathrm{x}}$. The rates of 1-alkene epoxidation are $\sim 10$-fold greater in Ti-FAU-OH than Ti-FAU-F (Fig. 4a) and depend weakly on the chain length of the 1-alkene. Turnover rates for 1-hexene epoxidation are 60-times higher within TiBEA-OH in comparison to Ti-BEA-F (Fig. 4b), and the difference between rates in hydrophilic and hydrophobic variants increases with 1-alkene chain length to a difference of 150-fold for 1-decene. Finally, the ratio of epoxidation rates within Ti-MFI-OH to those in Ti-MFI-F increase from a ratio of 100x to 400x as the 1-alkene is changed from 1-hexene to 1-decene (Fig. 4c). These differences in turnover rates among Ti-zeolites and 1-alkenes do not reflect differences in the mechanism for epoxidation ${ }^{5,18,39}$ or differences in 
the electronic properties of the active sites. ${ }^{5,18,39}$ Rather, vast range of epoxidation rates among Ti-zeolite with distinct topologies and $(\mathrm{SiOH})_{\mathrm{x}}$ densities reflects differences between the structures of solvent molecules that solvate reactive intermediates and transition states at Ti active sites and that recognize the shape, size, and polarity of the surrounding voids.
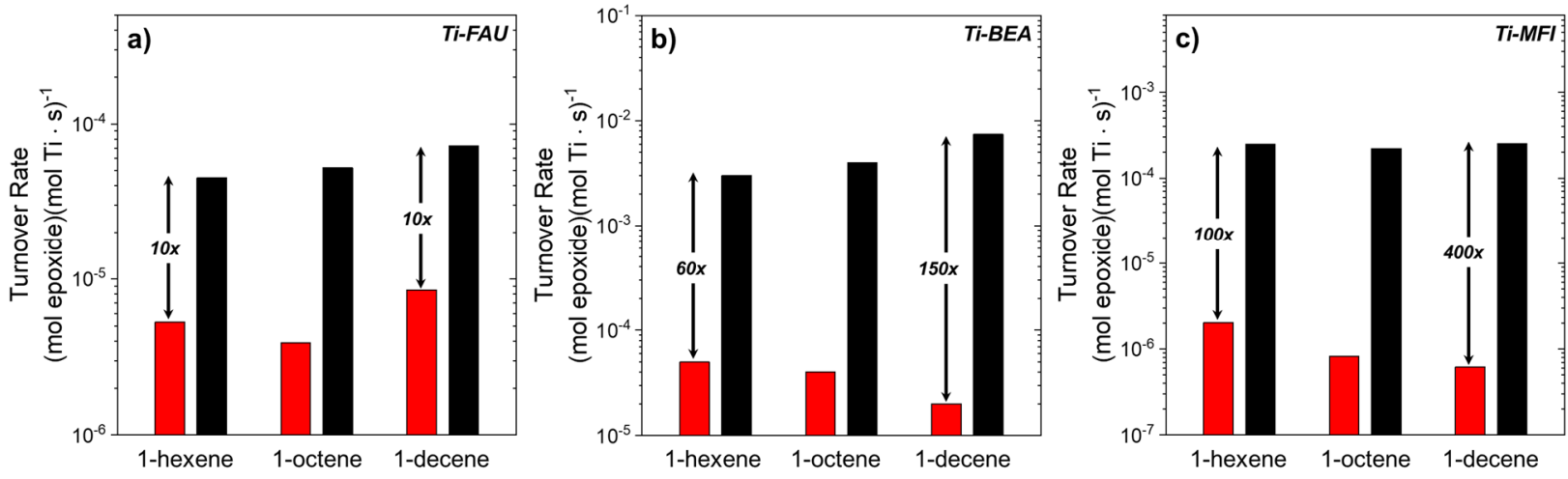

Figure 4. Turnover rates for 1-alkene epoxidation with $\mathrm{H}_{2} \mathrm{O}_{2}$ over Ti-zeolites of varying $(\mathrm{SiOH})_{x}$ densities. Turnover rates for 1-hexene, 1-octene, and 1-decene epoxidation $\left(0.5 \mathrm{mM} 1\right.$-alkene, $10 \mathrm{mM} \mathrm{H}_{2} \mathrm{O}_{2}$ and $39 \mathrm{mM} \mathrm{H}_{2} \mathrm{O}$ ) over a, Ti-FAU-F (red) and Ti-FAU-OH (black), b, Ti-BEA-F (red) and Ti-BEA-OH (black), and c, Ti-MFI-F (red) and Ti-MFI-OH (black) in $\mathrm{CH}_{3} \mathrm{OH}$ at $313 \mathrm{~K}$. In all cases, reactions were conducted under conditions where rates reflect kinetically relevant $\mathrm{O}$-atom transfer and $\mathrm{Ti}$ active sites are saturated with Ti-OOH and Ti- $\left(\eta^{2}-\mathrm{O}_{2}\right)$ intermediates.

Silanol functions that neighbor Ti active sites nucleate structures of $\mathrm{H}_{2} \mathrm{O}$ that reorganize in response to the individual elementary steps during epoxidation catalysis. ${ }^{5,6}$ The extent by which solvent molecules must restructure depends on the dimensions of the reactive intermediates, the initial structure of the solvent molecules (that depend on zeolite topology and polarity), and the type and strength of specific interactions between the solvent and reactive species. ${ }^{18}$ Consequently, the size of the 1-alkene correlates to the average number of hydrogen bonds and solvent molecules disturbed to accommodate the surface intermediates and transition states for epoxidation. Under reaction conditions where the concentration of $\mathrm{H}_{2} \mathrm{O}_{2}$ exceeds that of the 1-alkene, ${ }^{5,39,59}$ pools of Ti-OOH and Ti- $\left(\eta^{2}-\mathrm{O}_{2}\right)$ intermediates comprise the most abundant reactive intermediate (MARI; collectively denoted as Ti-OOH) which leads to the following rate expression for alkene epoxidation

$$
\frac{r_{E}}{[L]}=\frac{k_{b} T}{h} e^{\left(\frac{-\Delta G_{A p p}^{\ddagger}}{R T}\right)}[\text { alkene }]
$$

where $r_{E}$ is the rate of epoxidation, $[L]$ is the total number of Ti atoms, $T$ is the absolute temperature in Kelvin, $k_{b}, h$, and $R$ are the Boltzmann, Planck, and ideal gas constants, respectively, $\Delta G_{A p p}^{\ddagger}$ is the apparent free energy of activation, and [alkene] is the fluid-phase concentration of the alkene.

Born-Haber thermochemical cycles provide a conceptual framework to deconstruct an apparent change in free energy between two states into individual contributions from distinct chemical processes. ${ }^{18,21,60}$ Scheme 1 shows a series of chemical steps that conveniently deconvolutes measured values 
of $\Delta G_{A p p}^{\ddagger}$ into specific chemical interactions within Ti-zeolites that possess low (Scheme 1a) or high (Scheme $1 b)$ densities of $(\mathrm{SiOH})_{x}$. In this sequence, fluid-phase alkene molecules enter the pores of the Tizeolite, displace solvent molecules, and interact with the surrounding pore walls, which corresponds to a free energy of adsorption $\left(\Delta G_{A d s}\right)$ that depends primarily on the characteristic size of the surrounding pores. Next, solvent molecules localized near $\mathrm{Ti}$ active sites must reorganize to accommodate the 1-alkene conformation that positions the $\mathrm{C}=\mathrm{C}$ with $\mathrm{Ti}-\mathrm{OOH}$ intermediates prior to $\mathrm{O}$-atom transfer $\left(\Delta G_{\text {excess }}\right)$. Finally, the events that lead to $\mathrm{O}$-atom transfer between the Ti-OOH and the $\mathrm{C}=\mathrm{C}$ is described by an intrinsic free energy of activation $\left(\Delta G_{I n t}^{\ddagger}\right)$ that depends only on the identity of the active metal atom. ${ }^{18,39,40,59}$ In this conceptual framework, values of $\Delta G_{A p p}^{\ddagger}$ are given by

$$
\Delta G_{A p p}^{\ddagger}=\Delta G_{I n t}^{\ddagger}+\Delta G_{A d s}+\Delta G_{\text {excess }}
$$

We have shown that $\Delta G_{I n t}^{\ddagger}$ does not depend on the size of the confining pore $18,39,40,61$ or the density of $(\mathrm{SiOH})_{\mathrm{x}},{ }^{5}$ because $\Delta G_{\text {Int }}^{\ddagger}$ corresponds to the free energy required to exchange electrons between Ti-OOH species and the $\mathrm{C}=\mathrm{C}$ following all changes to the configuration of the alkene and solvent. Alkenes preferentially associate with hydrophobic, siloxane regions of the pores upon adsorption within the zeolite; therefore, values of $\Delta G_{A d s}$ primarily reflect differences in the characteristic pore size and do not depend significantly on $(\mathrm{SiOH})_{\mathrm{x}}$ density. ${ }^{8,18,39}$ Then, this framework suitably attributes all changes in $\Delta G_{A p p}^{\ddagger}$ caused by solvent restructuring about the transition state complex to the excess interaction between that transition state and surrounding solvation shells, which $\Delta G_{\text {excess }}$ captures. The hydrophobic Ti-zeolites contain exceedingly few $(\mathrm{SiOH})_{\mathrm{x}}$ proximate to $\mathrm{Ti}$ active sites, and as such, the local solvent structures predominantly consist of non-hydrogen bonded $\mathrm{CH}_{3} \mathrm{CN}$ molecules that require insignificant reorganization energies and offer a convenient point of reference. As such, we set the $\Delta G_{\text {excess }}$ of Ti-zeolite-F materials to be equal to zero for the purposes of these comparisons. This analysis provides differences between $\Delta G_{A p p}^{\ddagger}$ that for a given zeolite topology reflect the disruption and reorganization of $\mathrm{H}_{2} \mathrm{O}$ molecules near Ti active sites within the hydrophilic Ti-zeolites.

$$
\left.\Delta G_{A p p}^{\ddagger}\right|_{\text {Hydrophilic }}-\left.\Delta G_{\text {App }}^{\ddagger}\right|_{\text {Hydrophobic }}=\Delta G_{\text {excess }}
$$

Here, $\Delta G_{\text {excess }}$ quantifies the free energy difference caused by the disruption of hydrogen bonding interactions among $\mathrm{H}_{2} \mathrm{O}$ and solvent molecules as these species reorganize to accommodate the formation of the reactive intermediate that precedes the epoxidation transition state, which strongly resembles the transition state itself. 
Scheme 1. Born-Haber thermochemical cycle that describes the hypothetical elementary steps to form epoxidation transition states over Ti-zeolites. ${ }^{a}$ a, Hydrophilic Ti-zeolites that contain few $\mathrm{H}_{2} \mathrm{O}$ molecules near Ti active sites and $\mathbf{b}$, hydrophobic materials with $(\mathrm{SiOH})_{\mathbf{x}}$ functions near active sites that entrain $\mathrm{H}_{2} \mathrm{O}$ molecules proximate to reaction centers.
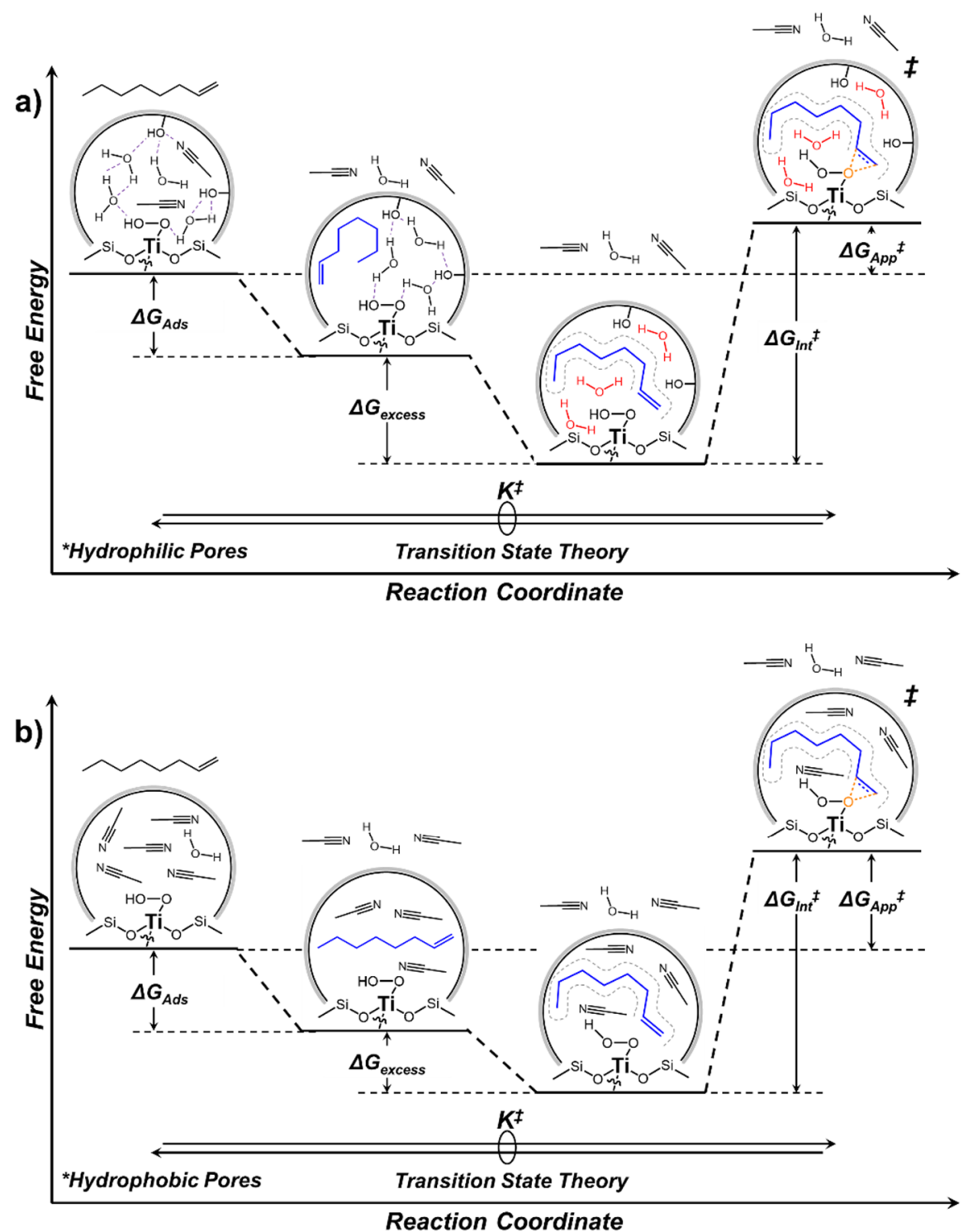

${ }^{a} \mathrm{Ti}-\mathrm{OOH}$ intermediates and fluid-phase alkene represent the reference states that are in equilibrium with the formation of the transition states for epoxidation, which is described by a transition state equilibrium constant $\left(K^{*}\right)$ and an apparent activation free energy $\left(\Delta G_{A p p^{*}}\right)$. This reaction sequence involves the adsorption of the alkene (depicted as 1-octene) into the pores of the Ti-zeolite $\left(\Delta G_{A d s}\right)$, the reorganization of solvent molecules, Ti-OOH intermediates, and intraporous alkene $\left(\Delta G_{\text {excess }}\right)$, and charge transfer between the Ti-OOH intermediate the $\mathrm{C}=\mathrm{C}$ to form the transition state $\left(\Delta G_{I n t}\right)$. The dashed lines in $\mathbf{b}$ represent hypothetical hydrogen bonds between $(\mathrm{SiOH})_{\mathrm{x}}$ and $\mathrm{H}_{2} \mathrm{O}$ molecules, while the dashed curve in states 3 and 4 in $\mathbf{a}$ and $\mathbf{b}$ represent the conformation of the alkene, Ti-OOH, and solvent molecules that is required prior to O-atom transfer. 


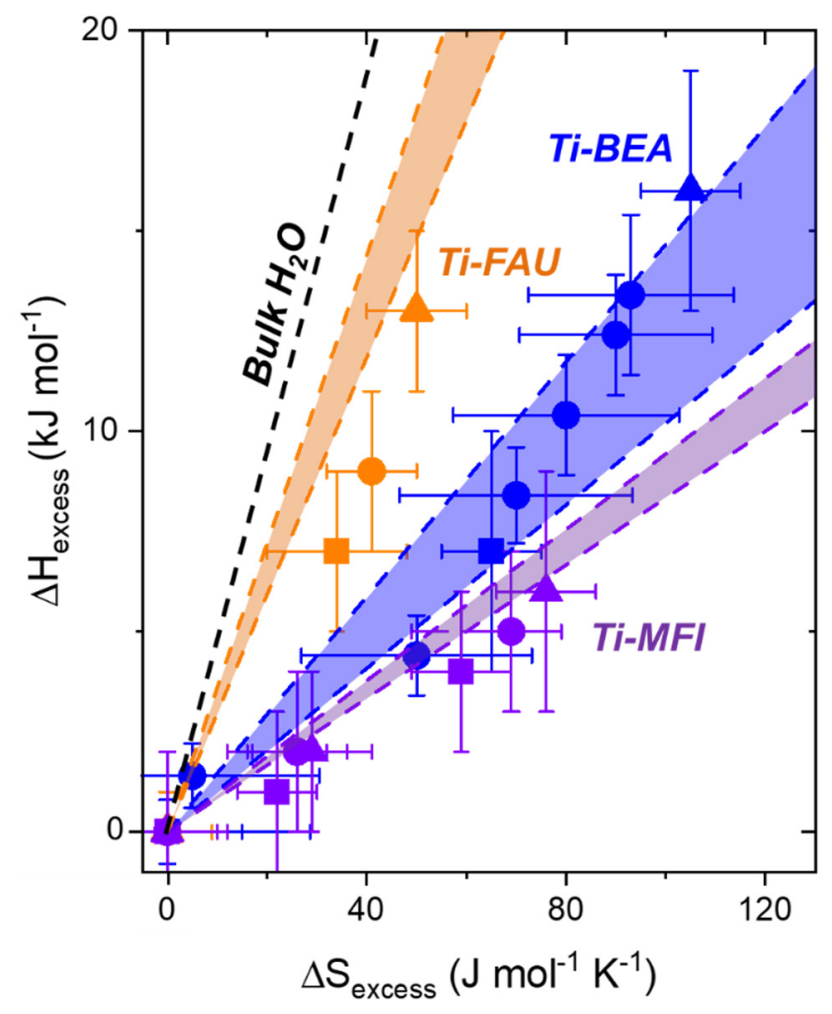

Figure 5. Enthalpy ( $\left.\Delta \mathrm{H}_{\text {excess }}\right)$ and entropy ( $\left.\Delta \mathrm{S}_{\text {excess}}\right)$ compensation relationships for disruption of confined $\mathrm{H}_{2} \mathrm{O}$ structures within Ti-FAU, Ti-BEA, and Ti-MFI. Values of $\Delta \mathrm{H}_{\text {excess }}$ as a function of $\Delta \mathrm{S}_{\text {excess }}$ for 1-hexene $(\boldsymbol{\bullet})$, 1-octene $(\bullet)$ and 1-decene $(\boldsymbol{\Delta})$ epoxidation reactions in Ti-FAU (orange), TiBEA (blue), and Ti-MFI (purple) zeolites. Values of $\Delta \mathrm{H}_{\mathrm{App}}{ }^{\ddagger}$ and $\Delta \mathrm{S}_{\mathrm{App}}{ }^{\ddagger}$ for each combination of 1-alkene and Ti-zeolite are in Tables S3 - S5. The dashed lines represent the values of $\Delta \mathrm{H}_{\mathrm{HB}}$ and $\Delta \mathrm{S}_{\mathrm{HB}}$ measured via variable temperature IR spectroscopy in the bulk fluid phase (black) or in Ti-FAU (orange), Ti-BEA (blue), and Ti-MFI (purple). The upper line for each of the Ti-zeolites corresponds to the most hydrophilic material, while the lower linear corresponds to the most hydrophobic sample. The shaded region is intended to represent the span of enthalpy - entropy compensation expected within these different pore environments due to the differences in $(\mathrm{SiOH})_{\mathrm{x}}$ for a given zeolite topology.

Figure 5 shows values of values of $\Delta \mathrm{H}_{\text {excess }}$ increase linearly with $\Delta \mathrm{S}_{\text {excess }}$ for 1-alkene epoxidations within Ti-FAU, Ti-BEA, and Ti-MFI catalysts, which reflects enthalpy-entropy $(\mathrm{H}-\mathrm{S})$ compensation effects widely reported for catalytic reactions ${ }^{6,8,9,20,62-64}$ and intimately tied to the dynamic restructuring of $\mathrm{HB}$ networks of $\mathrm{H}_{2} \mathrm{O}$ molecules within the zeolite pores (Fig. 1, Table 1). The values of $\Delta \mathrm{H}_{\text {excess }}$ and $\Delta \mathrm{S}_{\text {excess }}$ increase in proportion to one another with increasing 1-alkene chain length, which suggests that the perturbation of $\mathrm{H}_{2} \mathrm{O}$ molecules, and consequently values of $\Delta \mathrm{H}_{\text {excess }}$ and $\Delta \mathrm{S}_{\text {excess, }}$, increase with the number of methylene units of the reactants. Within Ti-FAU, values of $\Delta \mathrm{G}_{\text {excess }}$ (at $313 \mathrm{~K}$, via $\Delta \mathrm{G}_{\text {excess }}=\Delta \mathrm{H}_{\text {excess }}+$ $\mathrm{T} \Delta \mathrm{S}_{\text {excess }}$ ) lie near $0 \mathrm{~kJ} \mathrm{~mol}^{-1}$, which agrees with rate ratios for 1-alkene epoxidation over Ti-FAU-OH and Ti-FAU-F that do not depend on alkene chain length (Fig. 4a). In contrast, values of $\Delta \mathrm{G}_{\text {excess }}$ become increasingly negative with chain length or $(\mathrm{SiOH})_{\mathrm{x}}$ density within Ti-BEA zeolites, because the entropy gain associated with disrupting $\mathrm{H}_{2} \mathrm{O}$ clusters confined within BEA pores overwhelms the enthalpic cost of reorganizing these molecules. These comparisons reveal the molecular origins for epoxidation rate ratios that increase with 1-alkene chain length in Ti-BEA-OH and Ti-BEA-F (Fig. 4b). The same phenomenon 
appears also within Ti-MFI materials only to a larger extent with rate ratios between Ti-MFI-OH to TiMFI-F that reach a factor of 400 for 1-decene epoxidation (Fig. 4c). These greater gains in $\Delta \mathrm{S}_{\text {excess }}$ for epoxidation transition states in Ti-MFI reflect the low value for $\left\langle\mathrm{N}_{\mathrm{HB}}\right\rangle$, in comparison to other zeolite frameworks, which give rise to larger entropy gains by liberating $\mathrm{H}_{2} \mathrm{O}$ molecules for the minimal enthalpic cost (Table 1).

The observed H-S compensation effects via epoxidation catalysis (i.e., $\Delta \mathrm{H}_{\text {excess }}$ and $\Delta \mathrm{S}_{\text {excess}}$ ) are quantitatively consistent with the experimentally measured changes in enthalpies and entropies associated with disrupting $\mathrm{H}_{2} \mathrm{O}$ solvent structures (i.e., $\Delta \mathrm{H}_{\mathrm{HB}}$ and $\Delta \mathrm{S}_{\mathrm{HB}}$; Fig. 5) within these same pore environments. Figure 5 shows the $\mathrm{H}-\mathrm{S}$ compensation that originates from $\Delta \mathrm{H}_{\mathrm{HB}}$ and $\Delta \mathrm{S}_{\mathrm{HB}}$ measured independently via IR spectroscopy (vide supra) within bulk $\mathrm{H}_{2} \mathrm{O}$ and $\mathrm{H}_{2} \mathrm{O}$ filled pores of Ti-zeolite catalysts. The excellent agreement between kinetic and spectroscopic measurements testifies to the control that solvent reorganization processes hold over the stability of adsorbates and reactive intermediates (e.g., epoxidation transition states). Significantly, the H-S compensation relationship obtained from analysis of IR spectra do not rely on the presence of a reactant and do not arise from measurements of specific catalytic reaction rates, therefore, these measurements strongly suggest that many other catalytic reactions will be governed by these same compensation phenomena within pores of these zeolites within aqueous solvents. Here, hydrogen bonded $\mathrm{H}_{2} \mathrm{O}$ molecules within confining pores $(<1.3 \mathrm{~nm})$ possess entropies that are much lower than bulk $\mathrm{H}_{2} \mathrm{O}$ as a result of the highly correlated molecular motion imparted by the surrounding pores. ${ }^{57,58}$ The disruption of these rigid $\mathrm{H}_{2} \mathrm{O}$ structures results in an entropic gain that is much larger than observed in bulk $\mathrm{H}_{2} \mathrm{O}$, which leads to entropy-dominated decreases in the free energy of the system. In summary, this work gives compelling evidence for how the structure of intraporous solvent molecules and the reorganization of these solvent structures to accommodate the formation of reactive surface intermediates lead to consequential changes in the stability of reactive surface intermediates and large changes in the rates of reactions.

\section{Conclusions and Outlook:}

The structures of hydrogen bonded $\mathrm{H}_{2} \mathrm{O}$ solvent clusters depend sensitively on the shape and size of the surrounding void. Within $1.3 \mathrm{~nm}$ cavities, $\mathrm{H}_{2} \mathrm{O}$ molecules coalesce into three-dimensional clusters that resemble bulk liquid. In contrast, $\mathrm{H}_{2} \mathrm{O}$ within sub-nanometer pores form short largely one-dimensional chains of molecules that exist throughout the pore structure and possess cross-linking hydrogen bonds primarily at intersections between pores. During liquid-phase catalysis, these $\mathrm{H}_{2} \mathrm{O}$ structures must reorganize to accommodate the formation of reactive surface intermediates which leads to disproportionate increases in entropy that outweigh the enthalpic penalty for disrupting these confined solvent molecules. These phenomena likely affect a wide range of catalytic reactions that proceed within zeolite pores filled with aqueous solvents, and these reactions should therefore follow the enthalpy-entropy compensation relationships described here (Table 1).

The understanding developed here applies broadly, because the chemical interactions among polar $\mathrm{SiOH}$ functions, reactive intermediates, metal active sites, and protic solvents are recognized to strongly affect multiple classes of reactions that occur within microporous catalysts including methanol-to-hydrocarbons (MTH), ${ }^{65,66}$ alkene epoxidations, ${ }^{5,6,67-69}$ glucose isomerization, ${ }^{33-35,70}$ alcohol dehydration, $, 36,71$ transfer hydrogenation, ${ }^{8}$ and Baeyer-Villiger oxidation ${ }^{72}$ reactions. These data and interpretations clarify how the proximity of hydrogen-bonded solvent structures to reactive metal atoms leads to significant changes in the free energies of reactive intermediates via solvent reorganization. The condensation of protic molecules within zeolite pores may lead to the formation of extended solvent structures even during gas-phase 
catalysis. As such, similar phenomena should be considered in these circumstances. These concepts should also be considered examine in the context of optimizing rate, selectivities, and yields for catalytic conversions. Our findings demonstrate that the zeolite framework may be viewed as a way to escape the single-factor linear free energy relationships that link the stabilization of the reactant in a solvent to the stability of the transition state. Combinations of solvents (single or multicomponent) and microporous frameworks (zeolite, metal-organic-frameworks, or covalent-organic-frameworks) may be identified that make use of these emergent enthalpy-entropy compensation effects. While previous discoveries in this area often involved some level of serendipity, the comparisons demonstrated here suggest rational approaches for harnessing solvent, zeolite, reactant interactions to improve catalyst performance by significant margins. On-going work within our group seeks to understand how the structure of protic solvents and aqueousorganic solvent mixtures influence catalytic reactions and to exploit the characteristics of these hydrogen bonded solvation shells.

\section{Materials and Methods:}

\section{Ti-Zeolite Synthesis}

Titanium butoxide (TiBO; Sigma-Aldrich, 97\%, reagent grade), niobium ethoxide (NbEO; Sigma-Aldrich, 99.95\%, trace metals basis), tantalum ethoxide (TaEO; Sigma-Aldrich, 99.98\%, trace metals basis), tetraethylorthosilicate (TEOS, Sigma-Aldrich, 98\%, reagent grade), tetrapropylammonium hydroxide (TPAOH; Sachem, 40\% in $\mathrm{H}_{2} \mathrm{O}$ ), hydrofluoric acid (HF; Sigma-Aldrich, $48-50 \%$ in $\mathrm{H}_{2} \mathrm{O}$ ), titanium tetrachloride (Sigma-Aldrich, 99.9\%), dichloromethane (Fisher Chemicals, Certified ACS grade), nitric acid $\left(\mathrm{HNO}_{3}\right.$; Macron Chemicals, 68-70 wt. \%), tetraethylammonium fluoride (TEAF; Alfa Aesar, 97 wt. \%), titanium isopropoxide (TIPO; Sigma-Aldrich, 99.999\%), diethyldimethylammonium hydroxide (DEDMA-OH; Sachem, $20 \%$ in $\mathrm{H}_{2} \mathrm{O}$ ), fumed silica (Aerosil 90; 99.6 wt.\% $\mathrm{SiO}_{2}$ ), Air (Airgas, Ultra-zero grade), $\mathrm{H}_{2} \mathrm{O}(18.2 \mathrm{M} \Omega \cdot \mathrm{cm}$ ), and $\mathrm{Al}$-form BEA and FAU zeolites (see table 2 for manufacturer and $\mathrm{Si} / \mathrm{Al}$ ratios) were used as received.

Table 2. Al-BEA and Al-FAU Samples Used for Post-Synthetic Modification to Form Ti-Zeolite Catalysts.

\begin{tabular}{ccc}
\hline Sample & Zeolite Vendor & Initial Si/Al Ratio \\
\hline Al-BEA & Zeolyst & 12.5 \\
Al-BEA & Tosoh & 14 \\
Al-BEA & Tosoh & 20 \\
Al-BEA & ACS Material & 75 \\
Al-BEA & Zeolyst & 150 \\
Al-BEA & Tosoh & 250 \\
Al-FAU & Zeolyst & 15 \\
Al-FAU & Zeolyst & 385
\end{tabular}

Six of seven Ti-BEA and all Ti-FAU samples were prepared by post-synthetic modification (Table S1). Alzeolites were refluxed in $\mathrm{HNO}_{3}$ (Macron Chemicals, 68-70 wt. \%; $20 \mathrm{~cm}^{3} \mathrm{~g}_{\mathrm{Al}-\mathrm{BEA}}{ }^{-1}$; caution: $\mathrm{HNO}_{3}$ is a strong oxidant, readily causes a chemical burn, and should be handled carefully) with the intent to remove framework $\mathrm{Al}$ atoms by forming soluble $\mathrm{Al}\left(\mathrm{NO}_{3}\right)_{3}$. The solids were then recovered by vacuum filtration and washed with $\mathrm{H}_{2} \mathrm{O}\left(50 \mathrm{~cm}^{3} \mathrm{~g}^{-1}\right)$ followed by heating at $5 \mathrm{~K} \mathrm{~min}^{-1}$ in flowing air $\left(100 \mathrm{~cm}^{3} \mathrm{~min}^{-1}\right)$ and held at $823 \mathrm{~K}$ for $6 \mathrm{~h}$ to remove residual volatile and organic species and to produce siliceous materials. Materials produced in this manner possessed Si:Al ratios greater than 1400, as determined by energy dispersive X- 
ray fluorescence spectroscopy. Ti atoms were incorporated by combining a stirred suspension of Si-zeolite with an appropriate amount of $\mathrm{TiCl}_{4}$ in $\mathrm{CH}_{2} \mathrm{Cl}_{2}$ at reflux. Caution: TiCl 4 reacts violently with moisture in the air to form $\mathrm{HCl}$ and should be handled carefully. All volatile components were then removed by rotary evaporation. The recovered solids were light-brown, and these materials were heated in flowing air (100 $\mathrm{cm}^{3} \mathrm{~min}^{-1}$ ) at $5 \mathrm{~K} \mathrm{~min}^{-1}$ to $823 \mathrm{~K}$ and held at that temperature for $6 \mathrm{~h}$, which produced bright white solid powders.

Ti-BEA-F was synthesized hydrothermally in fluoride media by adapting a previously published procedure. ${ }^{70,73}$ TEAF was dissolved in deionized $\mathrm{H}_{2} \mathrm{O}$ in a polypropylene container and combined with TIPO to produce a clear homogeneous solution. TEOS was then added slowly over a period of one minute to this solution under static conditions, which initially formed a biphasic mixture. The mixture was then stirred for $16 \mathrm{~h}$ to produce an opaque homogeneous solution. The lid to the polypropylene container was then removed to evaporate the ethanol and isopropanol that form through the hydrolysis of the TEOS and TIPO, respectively. The solution was left open while stirring until the mass of the solution decreased by $115 \%$ of the value of the estimated mass of the alcohols to ensure that the alcohols evaporated completely. Subsequently, deionized $\mathrm{H}_{2} \mathrm{O}$ was added to yield a gel with a final molar composition of $1 \mathrm{SiO}_{2}: 0.0033$ TIPO: 0.56 TEAF: $7 \mathrm{H}_{2} \mathrm{O}$. This gel was then loaded into a Teflon-lined stainless-steel autoclave (Parr instruments, $45 \mathrm{~cm}^{3}$ ) that contained $5 \mathrm{wt}$. \% (relative to $\mathrm{SiO}_{2}$ within the gel) dealuminated BEA as seeds to promote the formation of the BEA zeolite framework. This autoclave was then sealed and heated to $413 \mathrm{~K}$ while rotating $(60 \mathrm{rpm})$ in a convection oven (Yamato, DKN602C) for 25 days. The resultant solids were recovered, washed with $\mathrm{H}_{2} \mathrm{O}$, and dried for $16 \mathrm{~h}$ at $373 \mathrm{~K}$. The dried solids were then heated at $1 \mathrm{~K} \mathrm{~min}^{-1}$ to $823 \mathrm{~K}$ in flowing air $\left(100 \mathrm{~cm}^{3} \mathrm{~min}^{-1}\right)$ and held at $823 \mathrm{~K}$ for $10 \mathrm{~h}$ to produce a bleached-white solid.

Ti-MFI was synthesized hydrothermally in either hydroxide or fluoride media. A desired amount of the TiBO precursor was dissolved in $27.7 \mathrm{~g}$ of TEOS in a polypropylene bottle with a screw cap to form a homogeneous solution that was subsequently cooled to $273 \mathrm{~K}$. Separately, a mixture of $28.7 \mathrm{~g}$ of TPAOH and $50.5 \mathrm{~g}$ of $\mathrm{H}_{2} \mathrm{O}$ was cooled to $273 \mathrm{~K}$ and was added slowly (over a period of $\sim 1 \mathrm{~min}$ ) to the TEOS solution, which yielded a biphasic mixture. This solution was warmed to $298 \mathrm{~K}$ and stirred for $12 \mathrm{~h}$ to produce a clear homogeneous solution, which indicates successful hydrolysis of the metal precursor and TEOS. The cover was then removed to completely evaporate the alcohol (e.g., ethanol, butanol) formed through hydrolysis of TEOS and the metal alkoxides. To ensure the complete evaporation of the alcohols, an additional $15 \mathrm{wt}$ \% of the calculated mass of the alcohols was evaporated over the course of $24-48 \mathrm{~h}$ and deionized $\mathrm{H}_{2} \mathrm{O}$ was added to make up for the excess liquid evaporated. This solution was then loaded into a Teflon-lined stainless-steel autoclave. While in the Teflon liner, a desired amount of HF (warning: $H F$ is extremely dangerous and should be handled very carefully) was added to the synthesis gel and stirred manually with a polypropylene spatula for $\sim 10$ seconds prior to gelation. Notably, the addition of at least an equimolar amount of HF, with respect to TPAOH, increases the viscosity of the synthesis gel significantly. These steps yield a gel with the approximate composition of $1 \mathrm{Si}: 0.0033 \mathrm{M}: 0.43 \mathrm{TPAOH}$ : $a \mathrm{HF}: 28.3 \mathrm{H}_{2} \mathrm{O}$, where $a$ depends on the amount of $\mathrm{HF}$ added. A small amount of Ti-MFI seeds (5\% by mass relative to $\mathrm{SiO}_{2}$ ) from a previous synthesis in $\mathrm{OH}^{-}$media were added to promote the crystallization of MFI. These autoclaves were then heated to $443 \mathrm{~K}$ while rotating $(30 \mathrm{rpm}$ ) in a convection oven for $3-7$ days. The resulting solids were recovered by centrifugation, washed with $\mathrm{H}_{2} \mathrm{O}$, and dried for $16 \mathrm{~h}$ at $373 \mathrm{~K}$. The dried solids were then heated in flowing air $\left(100 \mathrm{~cm}^{3} \mathrm{~min}^{-1}\right)$ to $823 \mathrm{~K} \mathrm{at} 1 \mathrm{~K} \mathrm{~min}^{-1}$ and held for $10 \mathrm{~h}$ to produce M-MFI materials that were bleached white in appearance.

Si-CDO was synthesized hydrothermally via the topotactic conversion of a pre-CDO layered silicate that to RUB-37 (i.e., Si-CDO). ${ }^{74}$ First, commercial DEDMA-OH solution was dehydrated until a concentration of $23.6 \%$ was reached. Then, $5.16 \mathrm{~g}$ of fumed silica was combined with $19.02 \mathrm{~g}$ of the preconcentrated DEDMA-OH solution. After 15 minutes stirring, a thick, white gel is yielded with a molar composition of $1 \mathrm{SiO}_{2}: 0.44$ DEDMA-OH $: 9.45 \mathrm{H}_{2} \mathrm{O}$. This gel was transferred into a teflon-lined autoclave, which was 
heated to $423 \mathrm{~K}$ in a convection oven for 13 days. The resulting solids were recovered by filtration, washed with $\mathrm{H}_{2} \mathrm{O}$, and dried at $353 \mathrm{~K}$ for $12 \mathrm{~h}$ to yield $3.70 \mathrm{~g}$ RUB-36 (i.e., a pre-CDO silicate). RUB-36 was then heated in flowing air to $923 \mathrm{~K}$ at $2 \mathrm{~K} \mathrm{~min}^{-1}$ and held for $4 \mathrm{~h}$ to produce Si-CDO, that is bleached white in appearance.

\section{Catalyst Characterization}

X-ray diffractograms were collected using one of three diffractometers (Siemens/Bruker, D5000; Bruker, D8; Bruker, D4) with a $\mathrm{Cu} \mathrm{K \alpha}$ radiation source $(0.15418 \mathrm{~nm})$ under ambient conditions (Figure S1).

Band edge energies (Table S1) were measured by diffuse reflectance UV-vis spectroscopy (DRUV-vis). In short, samples were intimately ground with magnesium oxide (MgO; Sigma-Aldrich, 99.995\%) in a 1:10 ratio of Ti-silicate to $\mathrm{MgO}$ by mass. These samples were loaded into a Harrick diffuse-reflectance accessory and spectra were obtained using a spectrophotometer (Agilent, CARY5) with pure $\mathrm{MgO}$ as the background.

Metal contents were quantified using energy dispersive X-ray fluorescence (EDXRF). Briefly, $\sim 30 \mathrm{mg}$ of the catalyst was loaded into a polypropylene sample holder $(1 \mathrm{~cm}$ diameter $)$ that was sealed with ultralene film. Samples were loaded into a spectrometer (Shimadzu, EDX-7000), whose sample chamber was purged with $\mathrm{He}$ (Airgas, Ultra-zero grade). Measurements were taken between $0-30 \mathrm{keV}$ (100 co-averaged scans), and the relative intensities of the element-specific fluorescence features were used to calculate the percent, by mass, of each element within the sample.

\section{Infrared Spectroscopy to Probe $\mathrm{H}_{2} \mathrm{O}$ Structure}

Attenuated total reflectance infrared (ATR-IR) spectroscopy was used to characterize the vibrational structure of $\mathrm{H}_{2} \mathrm{O}$ within the pores of zeolite samples with different densities of $(\mathrm{SiOH})_{\mathrm{x}}$. Zeolites $(\sim 30 \mathrm{mg})$ were first dispersed into $\mathrm{CH}_{3} \mathrm{CN}\left(\sim 1 \mathrm{~cm}^{3}\right)$ via sonication and were subsequently drip coated onto a $\mathrm{ZnSe}$ cylindrical internal reflection element (IRE; International Crystal Labs). The catalyst-coated IRE was loaded into an ATR flow cell (Axiom, TNL-120), which was mounted onto a Fourier-transform infrared spectrometer (Bruker, Vertex 70). The cell was heated by a resistive heating cartridge placed within the wall of the cell, which was controlled by an electronic temperature controller (Watlow, EZ-Zone). Samples were first pretreated at $423 \mathrm{~K}\left(5 \mathrm{~K} \mathrm{~min}^{-1}\right)$ for $2 \mathrm{~h}$ in flowing $\mathrm{He}\left(10 \mathrm{~cm}^{3} \mathrm{~min}^{-1}\right)$ to desorb $\mathrm{CH}_{3} \mathrm{CN}$ that was present from the catalyst deposition. Background spectra (2500 scans, $1 \mathrm{~cm}^{-1}$ resolution) were then taken at $303 \mathrm{~K}$ in $\mathrm{He} . \mathrm{H}_{2} \mathrm{O}$ was subsequently introduced $\left(1 \mathrm{~cm}^{-1} \mathrm{~min}^{-1}\right)$ using a high-pressure piston pump (SSI, Series 1$)$ and spectra (2500 scans, $1 \mathrm{~cm}^{-1}$ resolution) were acquired at a desired temperature $(303-343 \mathrm{~K})$.

To quantify the spectral contributions of $\mathrm{H}_{2} \mathrm{O}$ within the pores of the zeolites, 2,4,6-tri-tert-butylpyridine (2,4,6-ttbupy; Sigma-Aldrich, 99\%) was used as a probe molecule because it cannot fit into the 12membered ring pores of FAU or BEA. After the spectra of $\mathrm{H}_{2} \mathrm{O}$ were obtained on a given catalyst-coated crystal, a stream of $\mathrm{He}\left(10 \mathrm{~cm}^{3} \mathrm{~min}^{-1}\right)$ was flowed over the catalyst surface at $423 \mathrm{~K}\left(5 \mathrm{~K} \mathrm{~min}^{-1}\right)$ for $2 \mathrm{~h}$ to remove all $\mathrm{H}_{2} \mathrm{O}$. The IRE was subsequently cooled to $303 \mathrm{~K}$ and a spectrum of 2,4,6-ttbupy $(\sim 1 \mathrm{M})$ in $n$ hexane (Sigma-Aldrich, 99\%) was acquired. Comparisons of the recorded spectra over a zeolite-coated IRE to a clean IRE (Section S2.2) were made to distinguish the spectral contributions from within the zeolite pores from the bulk solution.

\section{Molecular Dynamics Simulations of $\mathrm{H}_{2} \mathrm{O}$ within Different Porous Environments}


The three-dimensional coordinates of each zeolite framework were obtained from the International Zeolite Association Structure Database. It should be noted that the BEA structure was chosen to model Ti-BEA materials. One Si atom for every 5 unit cells was random selected and substituted for a Ti atom. An additional constraint for Ti placement in Ti-MFI was introduced such that Ti atoms were sited in either T3, T7, T8, T10, or T12 positions as previously characterized by Hijar et al. ${ }^{75}$ For modeling zeolite pores with silanol defects, approximately $5(\mathrm{SiOH})_{4}$ defects per unit cell were randomly placed under the condition that defects may not occupy adjacent tetrahedral sites. Approximately 15 unit cells were constructed and solvated with TIP5P water molecules. ${ }^{76}$ The silica forcefields derived by Emami et al. ${ }^{77}$ were used to parameterize the zeolite framework. Parameters involving Ti atoms were obtained from UFF. ${ }^{78}$ The tleap package of AmberTools was used to construct the MD systems. ${ }^{79}$

The system was first minimized for 5,000 steps using the steepest descent method, followed by 45,000 steps using a conjugate gradient method. The system was then heated from $0 \mathrm{~K}$ to $313 \mathrm{~K}$ at NPT conditions. Production simulations were implemented using the AMBER18 molecular dynamics package ${ }^{79}$ using the pmemd GPU accelerated module ${ }^{80,81}$ under constant NPT conditions, periodic boundary conditions, and a 2 femtosecond integration timestep. Temperature $(313 \mathrm{~K})$ and pressure $(1 \mathrm{~atm})$ were maintained using Berendsen thermostat and barostat, respectively. ${ }^{82}$ Bonds involving hydrogen atoms were constrained using the SHAKE algorithm. ${ }^{83}$ Electrostatic interactions were treated using the Partial Mesh Ewald method with a nonbonded distance cutoff set at $10 \AA .{ }^{84}$ Each system was simulated for $1 \mu \mathrm{s}$. Trajectory snapshots were saved every 100 ps during production simulations and were visualized using Visual Molecular Dynamics (VMD) software. ${ }^{85}$

The average number of hydrogen bonds formed per water molecule $<\mathrm{N}_{\mathrm{HB}}>_{\mathrm{MD}}$ was calculated as the total number of hydrogen bonds formed normalized by the total number of water molecules within a given zeolite framework. Hydrogen bonds were further differentiated based on the identity of the donor-acceptor pair. Hydrogen bonds that involved the surface silanol groups were classified as water-surface (W-S) hydrogen bonds, while hydrogen bonds involving other water molecules were labeled as water-water (W-W) hydrogen bonds.

\section{Trajectory Analysis of Molecular Dynamics Simulations}

Trajectories were processed using the CPPTRAJ module of AMBER $18^{86}$ and MDtraj Python library. ${ }^{87}$ Hydrogen bonds were identified based on a distance cutoff of $3.5 \AA$ and angle cutoff of 120 degrees between

the acceptor and donor atom. ${ }^{8}$ In-house scripts and the matplotlib Python library were used to generate water distribution plots.

\section{Kinetic Measurements of 1-Alkene Epoxidation}

1-Hexene $\left(\mathrm{C}_{6} \mathrm{H}_{12}\right.$; Sigma-Aldrich, $\left.>99 \%\right)$, 1-heptene $\left(\mathrm{C}_{7} \mathrm{H}_{14}\right.$; TCI Chemicals, $\left.>98 \%\right)$, 1-octene $\left(\mathrm{C}_{8} \mathrm{H}_{16}\right.$; Sigma-Aldrich, $98 \%)$, 1-nonene $\left(\mathrm{C}_{9} \mathrm{H}_{18}\right.$, TCI Chemicals, $\left.>95 \%\right)$, 1-decene $\left(\mathrm{C}_{10} \mathrm{H}_{20}\right.$, TCI Chemicals, $\left.>95 \%\right)$, $\mathrm{H}_{2} \mathrm{O}_{2}$ (Fischer Chemicals, 30 wt. \% in $\mathrm{H}_{2} \mathrm{O}$ ), decane (TCI Chemicals, $>99 \%$ ), acetonitrile $\left(\mathrm{CH}_{3} \mathrm{CN}\right.$; Fisher Chemicals, HPLC Grade), and $\mathrm{H}_{2} \mathrm{O}(18.2 \mathrm{M} \Omega \mathrm{cm})$ were used as received.

Rates of alkene epoxidation and oxidant decomposition were measured using batch reactors $\left(100 \mathrm{~cm}^{3}\right.$, three-neck round-bottom flasks) equipped with reflux condensers to minimize evaporative losses. An alkene and $\mathrm{H}_{2} \mathrm{O}_{2}$ were added to a solution of $\mathrm{CH}_{3} \mathrm{CN}$ and decane (used as an internal standard for GC analysis) and heated to the desired temperature (303-348 K) while stirring at $700 \mathrm{rpm}$. The reactions were 
initiated by the addition of a catalyst, and small aliquots $(\sim 500 \mu \mathrm{L})$ of the reaction solution were extracted through a syringe filter $(0.22 \mu \mathrm{m}$, polypropylene $)$ at predetermined time intervals. The concentrations of the organic components within these aliquots were quantified via gas chromatography. All species were identified, and calibration factors were quantified using standards of known concentration. In all reported data, the standard uncertainty for measured reaction rates was below $10 \%$. For all reactions, only the 1,2epoxyalkane products were observed, which reflects the intentionally low conversion over which these experiments were conducted. Rates for the conversion of alkene and oxidant were determined using the method of initial rates and were measured as functions of reactant concentrations. All reported results were obtained at differential conversion (i.e., $<0.5 \%$ conversion of the limiting reagent); consequently, all reported rates do not reflect artifacts associated with catalyst deactivation. 1-Alkene epoxidation kinetics were measured in the absence of mass-transfer artifacts as indicated by turnover rates that depend linearly on the concentration of the alkene (data not shown). ${ }^{89}$ 


\section{Acknowledgements:}

D.T.B. was supported by the Department of Defense through the National Defense Science \& Engineering Graduate (NDSEG) Fellowship program and through a Dissertation Completion Fellowship from the University of Illinois. E.Z.A. was supported by the U.S. Army Research Office (W911NF-18-1-0100). This work was carried out, in part, in the Frederick Seitz Materials Research Laboratory. This research was supported by the Department of Energy, Office of Science, Office of Basic Energy Sciences, under Award DE-SC0020224. M.C. and D.S. acknowledge support from Blue Waters sustained-petascale computing project, which is supported by the National Science Foundation (awards OCI-0725070 and ACI1238993) the State of Illinois, and as of December 2019, the National Geospatial-Intelligence Agency. Blue Waters is a joint effort of the University of Illinois at Urbana-Champaign and its National Center for Supercomputing Applications.

\section{Contributions:}

D.T.B. and D.W.F. conceptualized the paper. D.T.B., J.Z.T., E.Z.A., and C.P.N. synthesized and characterized the zeolites. D.T.B. and J.Z.T. performed the spectroscopic and kinetic measurements. M.C. and D.S. performed the MD simulations. D.T.B. wrote the original draft of the manuscript and all authors reviewed and edited its content. D.S. and D.W.F. supervised the work.

\section{ORCID:}

Daniel T. Bregante: 0000-0003-2157-1286

Matthew Chan: 0000-0002-9826-1983

Jun Zhi Tan: 0000-0002-9643-2232

E. Zeynep Ayla: 0000-0002-9984-884X

Christopher P. Nicholas: 0000-0003-1461-3791

Diwakar Shukla: 0000-0003-4079-5381

David W: Flaherty: 0000-0002-0567-8481 


\section{References:}

1 Sievers, C. et al. Phenomena Affecting Catalytic Reactions at Solid-Liquid Interfaces. ACS Catalysis 6, 8286-8307, (2016).

2 Dyson, P. J. \& Jessop, P. G. Solvent Effects in Catalysis: Rational Improvements of Catalysts via Manipulation of Solvent Effects. Catal. Sci. Technol. 6, 3302-3316 (2016).

3 Bregante, D. T., Patel, A. Y., Johnson, A. M. \& Flaherty, D. W. Catalytic Thiophene Oxidation by Groups 4 and 5 Framework-Substituted Zeolites with Hydrogen Peroxide: Mechanistic and Spectroscopic Evidence for the Effects of Metal Lewis Acidity and Solvent Lewis Basicity. Journal of Catalysis 364, 415-425 (2018).

4 Anslyn, E. V. \& Dougherty, D. A. Modern Physical Organic Chemistry. (University Science, 2005).

5 Bregante, D. T. et al. Cooperative Effects between Hydrophilic Pores and Solvents: Catalytic Consequences of Hydrogen Bonding on Alkene Epoxidation in Zeolites. J Am Chem Soc 141, 7302-7319, (2019).

6 Bregante, D. T. \& Flaherty, D. W. Impact of Specific Interactions Among Reactive Surface Intermediates and Confined Water on Epoxidation Catalysis and Adsorption in Lewis Acid Zeolites. ACS Catalysis 9, 10951-10962, (2019).

7 Eckstein, S. et al. Influence of Hydronium Ions in Zeolites on Sorption. Angewandte Chemie International Edition 58, 3450-3455, (2019).

8 Di Iorio, J. R., Johnson, B. A. \& Roman-Leshkov, Y. Ordered Hydrogen-Bonded Alcohol Networks Confined in Lewis Acid Zeolites Accelerate Transfer Hydrogenation Turnover Rates. Journal of the American Chemical Society 142, 19379-19392, (2020).

9 Shetty, M. et al. Directing the rate-enhancement for hydronium ion catalyzed dehydration via organization of alkanols in nanoscopic confinements. Angew Chem Int Ed Engl, (2020).

10 Zhang, K. et al. Adsorption of water and ethanol in MFI-type zeolites. Langmuir 28, 8664-8673, (2012).

11 Zhang, K. et al. Alcohol and water adsorption in zeolitic imidazolate frameworks. Chem. Commun. 49, 3245-3247, (2013).

12 Lively, R. P. et al. Ethanol and water adsorption in methanol-derived ZIF-71. Chem. Commun. 47, 8667-8669, (2011).

13 Mallon, E. E., Jeon, M. Y., Navarro, M., Bhan, A. \& Tsapatsis, M. Probing the relationship between silicalite-1 defects and polyol adsorption properties. Langmuir 29, 6546-6555, (2013).

14 DeJaco, R. F. et al. Vapor- and liquid-phase adsorption of alcohol and water in silicalite-1 synthesized in fluoride media. AIChE Journal, (2020).

15 Thomas, J. A. \& McGaughey, A. J. H. Reassessing Fast Water Transport Through Carbon Nanotubes. Nano Letters 8, 2788-2793 (2008).

16 Majumder, M., Chopra, N., Andrews, R. \& Hinds, B. J. Enhanced flow in carbon nanotubes. Nature 438, 44, (2005).

17 Holt, J. K. et al. Fast Mass Transport Through Sub-2-Nanometer Carbon Nanotubes. Science 312, 1034-1037 (2006).

18 Bregante, D. T. et al. Catalytic Consequences of Oxidant, Alkene, and Pore Structure on Alkene Epoxidations within Titanium Silicates. ACS Catalysis 10, 10169-10184 (2020). 
19 Bregante, D. T. et al. Effects of Hydrofluoric Acid Concentration on the Density of Silanol Groups and Water Adsorption in Hydrothermally Synthesized Transition-Metal-Substituted Silicalite-1. Chemistry of Materials 32, 7425-7437 (2020).

20 Cordon, M. J. et al. Dominant Role of Entropy in Stabilizing Sugar Isomerization Transition States within Hydrophobic Zeolite Pores. J Am Chem Soc 140, 14244-14266, (2018).

21 Gould, N. S. et al. Understanding solvent effects on adsorption and protonation in porous catalysts. Nat Commun 11, 1060, (2020).

22 Ball, P. Water as an Active Constituent in Cell Biology. Chemical Reviews 108, 74-108, (2008).

23 Forneris, F. \& Mattevi, A. Enzymes Without Borders: Mobilizing Substrates, Delivering Products. Science 321, 213-216, (2008).

24 Snyder, P. W. et al. Mechanism of the hydrophobic effect in the biomolecular recognition of arylsulfonamides by carbonic anhydrase. Proc. Nat. Acad. Sci. 108, 17889-17894, (2011).

25 Hur, S., Newby, Z. E. R. \& Bruice, T. C. Transition state stabilization by general acid catalysis, water expulsion, and enzyme reorganization in Medicago savita chalcone isomerase. Proc. Nat. Acad. Sci. 101, 2730-2735, (2004).

26 Setny, P. \& Wisniewska, M. D. Water-mediated conformational preselection mechanism in substrate binding cooperativity to protein kinase A. Proc. Nat. Acad. Sci. 115, 3852-3857, (2018).

27 Grossman, M. et al. Correlated structural kinetics and retarded solvent dynamics at the metalloprotease active site. Nat. Struct. Mol. Bio. 18, 1102-1108, (2011).

28 Silverman, D. N. \& McKenna, R. Solvent-mediated proton transfer in catalysis by carbonic anhydrase. Acc. Chem. Res. 40, 669-675, (2007).

29 Harris, J. W., Bates, J. S., Bukowski, B. C., Greeley, J. \& Gounder, R. Opportunities in Catalysis over Metal-Zeotypes Enabled by Descriptions of Active Centers Beyond Their Binding Site. ACS Catalysis 10, 9476-9495, (2020).

30 Li, G., Wang, B. \& Resasco, D. E. Water-Mediated Heterogeneously Catalyzed Reactions. ACS Catalysis 10, 1294-1309, (2020).

31 Bates, J. S., Bukowski, B. C., Greeley, J. \& Gounder, R. Structure and solvation of confined water and water-ethanol clusters within microporous Brønsted acids and their effects on ethanol dehydration catalysis. Chem. Sci. 11, 7102-7122, (2020).

32 Bukowski, B. C., Bates, J. S., Gounder, R. \& Greeley, J. Defect-Mediated Ordering of Condensed Water Structures in Microporous Zeolites. Angew. Chem. Int. Ed. 58, 16422-16426 (2019).

33 Harris, J. W. et al. Titration and quantification of open and closed Lewis acid sites in Sn-Beta zeolites that catalyze glucose isomerization. J. Catalysis 335, 141-154, (2016).

34 Gounder, R. \& Davis, M. E. Monosaccharide and disaccharide isomerization over Lewis acid sites in hydrophobic and hydrophilic molecular sieves. J. Catalysis 308 (2013).

35 Vega-Vila, J. C. \& Gounder, R. Quantification of Intraporous Hydrophilic Binding Sites in Lewis Acid Zeolites and Consequences for Sugar Isomerization Catalysis. ACS Catalysis 10, 1219712211, (2020).

36 Wang, M. et al. Genesis and Stability of Hydronium Ions in Zeolite Channels. J. Am. Chem. Soc. 141, 3444-3455 (2019). 

from aqueous solution: isotherms, structural analysis, and assessment of ideal adsorbed solution theory. Langmuir 28, 15566-15576, (2012).

38 Wang, C.-H., Bai, P., Siepmann, J. I. \& Clark, A. E. Deconstructing Hydrogen-Bond Networks in Confined Nanoporous Materials: Implications for Alcohol-Water Separation. J. Phys. Chem. C 118, 19723-19732, (2014).

39 Bregante, D. T., Thornburg, N. E., Notestein, J. M. \& Flaherty, D. W. Consequences of Confinement for Alkene Epoxidation with Hydrogen Peroxide on Highly Dispersed Group 4 and 5 Metal Oxide Catalysts. ACS Catalysis 8, 2995-3010, (2018).

40 Bregante, D. T., Tan, J. Z., Sutrisno, A. \& Flaherty, D. W. Heteroatom substituted zeolite FAU with ultralow Al contents for liquid-phase oxidation catalysis. Catal. Sci. Tech. 10, 635-647 (2020).

41 Muñoz, M. A., Carmona, C. \& Balón, M. FTIR study of water clusters in water-triethylamine solutions. Chem. Phy. 335, 37-42, (2007).

42 Sun, Q. The Raman OH stretching bands of liquid water. Vib. Spectrosc. 51, 213-217, (2009).

43 Sun, Q. \& Guo, Y. Vibrational sum frequency generation spectroscopy of the air/water interface. J. Mol. Liq. 213, 28-32, (2016).

44 Sadlej, J. Theoretical study of structure and spectra of cage clusters (H2O)n, n = 11,12. Chem. Phys. Lett. 333, 485-492 (2001).

45 Zones, S. I. Conversion of Faujasites to High-Silica Chabazite SSZ-13 in the Presence of NNNTrimethyl-1-adamantammonium Iodide. J. Chem. Soc., Faraday Trans. 87, 3709-3716 (1991).

46 Zhou, T., Bai, P., Siepmann, J. I. \& Clark, A. E. Deconstructing the Confinement Effect upon the Organization and Dynamics of Water in Hydrophobic Nanoporous Materials: Lessons Learned from Zeolites. J. Phys. Chem. C 121, 22015-22024, (2017).

47 Fleys, M., Thompson, R. W. \& MacDonald, J. C. Comparison of the Behavior of Water in Silicalite and Dealuminated Zeolite Y at Different Temperatures by Molecular Dynamic Simulations. $J$. Phys. Chem. B 108, 12197-12203 (2004).

48 Nguyen, V. T. et al. A comparative study of the adsorption of water and methanol in zeolite BEA: a molecular simulation study. Mol. Simul. 40, 1113-1124, (2014).

49 Godawat, R., Jamadagni, S. N. \& Garde, S. Characterizing hydrophobicity of interfaces by using cavity formation, solute binding, and water correlations. Proc. Nat. Acad. Sci. 106, 15119-15124 (2009).

50 Chakraborty, S., Kumar, H., Dasgupta, C. \& Maiti, P. K. Confined Water: Structure, Dynamics, and Thermodynamics. Acc. Chem. Res. 50, 2139-2146, (2017).

51 Chandler, D. Interfaces and the driving force of hydrophobic assembly. Nature 437, 640-647, (2005).

52 Walrafen, G. E., Hokmabadi, M. S. \& Yang, W. H. Raman isosbestic points from liquid water. $J$. Chem. Phys. 85, 6964-6969, (1986).

53 Libnau, F. O., Kvalheim, O. M., Christy, A. A. \& Toft, J. Spectra of water in the near- and midinfrared region. Vib. Spectrosc. 7, 243-254 (1994).

54 McQuarrie, D. A. Statistical Mechanics. (University Science Books, 2000).

55 Silverstein, K. A. T., Haymet, A. D. J. \& Dill, K. A. The Strength of Hydrogen Bonds in Liquid Water and Around Nonpolar Solutes. J. Am. Chem. Soc. 122, 8037-8041 (2000). 
56 Walrafen, G. E. \& Chu, Y. C. Shear Viscosity, Heat Capacity, and Fluctuations of Liquid Water, All at Constant Molal Volume. J. Phys. Chem. 95, 8909-8921 (1991).

57 Striolo, A. Chapter 10 Nano-confined water. Theo. Comput. Chem. 18, 245-274 (2007).

58 Munoz-Santiburcio, D. \& Marx, D. Chemistry in nanoconfined water. Chem. Sci. 8, 3444-3452, (2017).

59 Bregante, D. T. \& Flaherty, D. W. Periodic Trends in Olefin Epoxidation over Group IV and V Framework Substituted Zeolite Catalysts: A Kinetic and Spectroscopic Study. J. Am. Chem. Soc. 139, 6888-6898, (2017).

60 Gounder, R. \& Iglesia, E. The catalytic diversity of zeolites: confinement and solvation effects within voids of molecular dimensions. Chem. Commun. 49, 3491-3509, (2013).

61 Ardagh, M. A., Bregante, D. T., Flaherty, D. W. \& Notestein, J. M. Controlled Deposition of Silica on Titania-Silica to Alter the Active Site Surroundings on Epoxidation Catalysts. ACS Catalysis 10, 13008-13018, (2020).

62 Cremer, E. The Compensation Effect in Heterogeneous Catalysis. Adv. Catal., 7, 75-91, 1955).

63 Flaherty, D. W. \& Iglesia, E. Transition-state enthalpy and entropy effects on reactivity and selectivity in hydrogenolysis of n-alkanes. J Am Chem Soc 135, 18586-18599, (2013).

64 Mellmer, M. A. et al. Solvent-Enabled Control of Reactivity for Liquid Phase Reactions of Biomass-Derived Compounds. Nature Catal. 1, 199-207 (2018).

65 Qin, Z. et al. Comparative Study of Nano-ZSM-5 Catalysts Synthesized in OH-and F-Media. Adv. Funct. Mater. 24, 257-264, (2014).

66 Grahn, M. et al. Small ZSM-5 crystals with low defect density as an effective catalyst for conversion of methanol to hydrocarbons. Catal. Today 345, 136-146, (2020).

67 Grosso-Giordano, N. A. et al. Outer-Sphere Control of Catalysis on Surfaces: A Comparative Study of Ti(IV) Single-Sites Grafted on Amorphous versus Crystalline Silicates for Alkene Epoxidation. $J$ Am Chem Soc 140, 4956-4960, (2018).

68 Grosso-Giordano, N. A. et al. Dynamic Reorganization and Confinement of Ti(IV) Active Sites Controls Olefin Epoxidation Catalysis on Two-Dimensional Zeotypes. J. Am. Chem. Soc. 141, 7090-7106, (2019).

69 Wang, L. et al. A significant enhancement of catalytic activities in oxidation with $\mathrm{H}_{2} \mathrm{O}_{2}$ over the TS-1 zeolite by adjusting the catalyst wettability. Chem. Commun. 50, 2012-2014, (2014).

70 Cordon, M. J. et al. The Dominant Role of Entropy in Stabilizing Sugar Isomerization Transition States within Hydrophobic Zeolite Pores. J. Am. Chem. Soc. 140, 14244-14266 (2018).

71 Eckstein, S. et al. Influence of Hydronium Ions in Zeolites on Sorption. Angew. Chem. Int. Ed. 58, 3450-3455 (2019).

72 Conrad, S., Wolf, P., Müller, P., Orsted, H. \& Hermans, I. Influence of Hydrophilicity on the Sn $\beta$ Catalyzed Baeyer-Villiger Oxidation of Cyclohexanone with Aqueous Hydrogen Peroxide. ChemCatChem 9, 175-182, (2017).

73 Blasco, T. et al. Direct synthesis and characterization of hydrophobic aluminum-free Ti-beta zeolite. J. Phys. Chem. B 102, 75-88 (1998).

74 Marler, B., Wang, Y., Song, J. \& Gies, H. Topotactic condensation of layer silicates with ferrieritetype layers forming porous tectosilicates. Dalton Trans. 43, 10396-10416, (2014). 
Hijar, C. A. et al. The Siting of Ti in TS-1 Is Non-Random. Powder Neutron Diffraction Studies and Theoretical Calculations of TS-1 and FeS-1. J. Phys. Chem. B 104, 12157-12164 (2000).

76 Horn, H. W. et al. Development of an improved four-site water model for biomolecular simulations: TIP4P-Ew. J. Chem. Phys. 120, 9665-9678, (2004).

77 Emami, F. S. et al. Force Field and a Surface Model Database for Silica to Simulate Interfacial Properties in Atomic Resolution. Chem. Mater., 26, 2647-2658, (2014).

Rappe, A. K., Casewit, C. J., Colwell, K. S., Goddard III, W. A. \& Skiff, W. M. UFF, a Full Periodic Table Force Field for Molecular Mechanics and Molecular Dynamics Simulations.J. Am. Chem. Soc., 114, 10024-10035 (1992).

79 Case, D. et al. AMBER 18; 2018. University of California, San Francisco.

80 Gotz, A. W. et al. Routine Microsecond Molecular Dynamics Simulations with AMBER on GPUs. 1. Generalized Born. J. Chem. Theo. Comput., 8, 1542-1555, (2012).

81 Salomon-Ferrer, R., Gotz, A. W., Poole, D., Le Grand, S. \& Walker, R. C. Routine Microsecond Molecular Dynamics Simulations with AMBER on GPUs. 2. Explicit Solvent Particle Mesh Ewald. J. Chem. Theo. Comput. 9, 3878-3888, (2013).

82 Berendsen, H. J. C., Postma, J. P. M., van Gunsteren, W. F., DiNola, A. \& Haak, J. R. Molecular dynamics with coupling to an external bath. J. Chem. Phys., 81, 3684-3690, (1984).

83 Kräutler, V., van Gunsteren, W. F. \& Hünenberger, P. H. A fast SHAKE algorithm to solve distance constraint equations for small molecules in molecular dynamics simulations. J. Comput. Chem. 22, 501-508 (2001).

84 York, D. M., Darden, T. A. \& Pedersen, L. G. The effect of long-range electrostatic interactions in simulations of macromolecular crystals: A comparison of the Ewald and truncated list methods. $J$. Chem. Phys., 99, 8345-8348, (1993).

85 Humphrey, W., Dalke, A. \& Schulten, K. VMD: Visual molecular dynamics. J. Molec. Graph. 14, 33-38 (1996).

86 Roe, D. R. \& Cheatham, T. E., 3rd. PTRAJ and CPPTRAJ: Software for Processing and Analysis of Molecular Dynamics Trajectory Data. J. Chem. Theo. Comput. 9, 3084-3095, (2013).

87 McGibbon, R. T. et al. MDTraj: A Modern Open Library for the Analysis of Molecular Dynamics Trajectories. Biophys. J., 109, 1528-1532, (2015).

88 Jeffrey, G. A. An Introduction to Hydrogen Bonding. Vol. 12 (Oxford University Press, 1997).

89 Chorkendorff, I. \& Niemantsverdriet, J. W. H. Concepts of Modern Catalysis and Kinetics. $2^{\text {nd }}$ edn, (Wiley-VCH Verlag Gmbh \& Co., 2007). 


\section{Graphical Abstract}

Kinetic, spectroscopic, and computational characterization of $\mathrm{H}_{2} \mathrm{O}$ structures reveals...

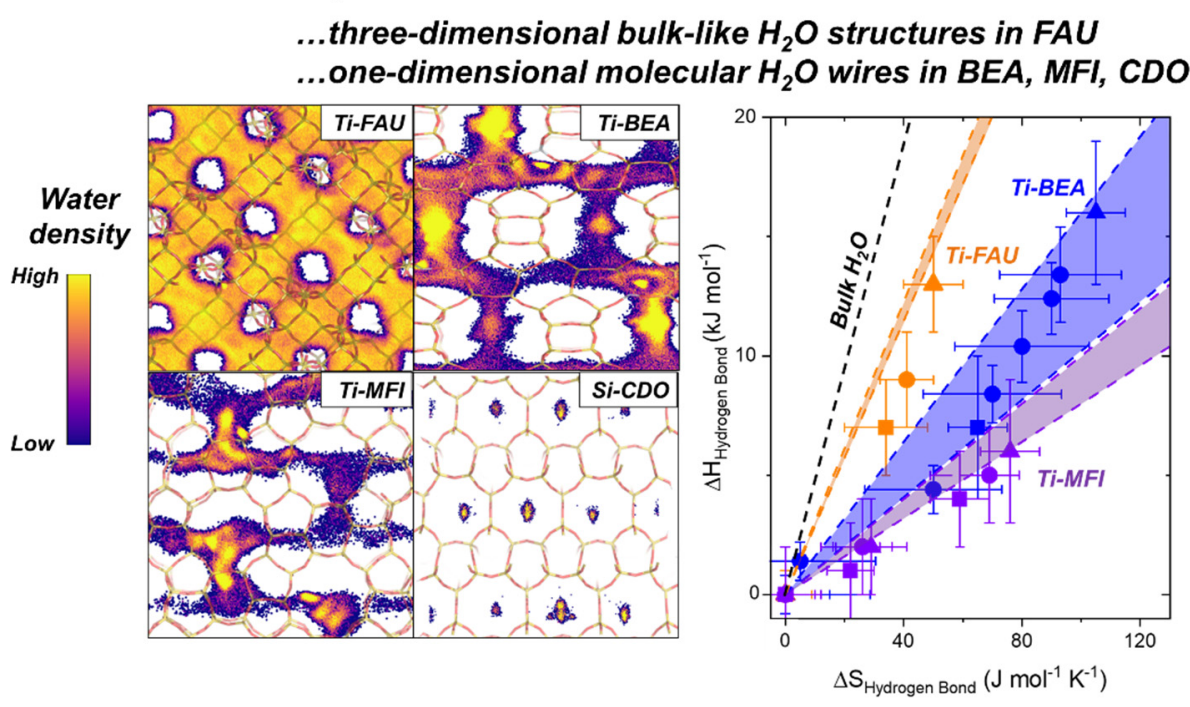

...disruption of confined $\mathrm{H}_{2} \mathrm{O}$ structures leads to topology-dependent $H$-S compensation effect and large changes in epoxidation rates 